\title{
Modelling effects of an asphalt road at a dike crest on dike cover erosion onset during wave overtopping
}

\author{
A. Bomers ${ }^{1}$ (D) J. P. Aguilar Lopez ${ }^{1,2}$ • J. J. Warmink ${ }^{1} \cdot$ \\ S. J. M. H. Hulscher ${ }^{1}$
}

Received: 24 April 2017/Accepted: 25 March 2018/Published online: 31 March 2018

(C) The Author(s) 2018

\begin{abstract}
Structures integrated in a grass-covered dike may increase erosion development. Currently, safety assessment methods for flood defences are only applicable for a conventional grass-covered dike and the effects of structures on dike cover erosion are poorly understood. Since many dikes have a road on top, it is important to study the effect of such a road structure on erosion onset during wave overtopping. To investigate this effect, a coupled hydrodynamic-erosion model was developed. The erosion onset caused by overtopping waves was predicted by combining the time-varying bed shear stresses from the hydrodynamic model with a depth-dependent erosion model. The results show that roads on top of a dike increase the erosion of the neighbouring grass cover. This increase in erosion may have a negative impact on dike stability. Therefore, we recommend considering effects of constructions on top of dike profiles during safety assessments. Explicitly, consideration of the roughness transitions in the safety assessments of dikes is recommended.
\end{abstract}

Electronic supplementary material The online version of this article (https://doi.org/10.1007/s11069-0183287-y) contains supplementary material, which is available to authorized users.

\author{
A. Bomers \\ a.bomers@utwente.nl \\ J. P. Aguilar Lopez \\ j.p.aguilarlopez@tudelft.nl \\ J. J. Warmink \\ j.j.warmink@utwente.nl \\ S. J. M. H. Hulscher \\ s.j.m.h.hulscher@utwente.nl
}

1 Department Water Engineering and Management, University of Twente, Dienstweg 1, 7522 NB Enschede, The Netherlands

2 Present Address: Department Water Management, Delft University of Technology, Delft, The Netherlands 
Keywords Flooding · Asphalt road · CFD simulation · Dike erosion · Bed shear stresses - Wave overtopping

\section{Introduction}

Waves overtopping a dike may cause erosion of the dike cover, which can ultimately result in a dike breach. Flooding caused by dike breach is one of the main hazards to cause large economic damage and human casualties worldwide as a result of serious inundations with disastrous effects. A recent example of such a disastrous event is Hurricane Katrina, which has led to many dike breaches caused by wave overtopping. Due to these dike breaches a large part of New Orleans was inundated.

Wave overtopping discharge is caused by waves, from either the sea, lakes, or rivers, running up the dike slope. If wave run-up levels exceed the crest level, the water tongue flows over the crest of the flood defence and runs down on the landside slope (Fig. 1) (EurOtop 2007). Wave overtopping differs from wave overflow as the discharge probability distribution during wave overtopping is somewhat triangular-shaped with a maximum discharge several times greater than the time-averaged discharge (Hughes and Nadal 2009). Under wave overtopping events, the force of individual waves can be much larger than in case of overflow.

Many dikes consist of a grass cover of approximately $10 \mathrm{~cm}$ with a clay layer between 50 and $70 \mathrm{~cm}$ of thickness and a sandy core (Van Hoven et al. 2010; Hoffmans 2012; Trung 2014a). Dike breach of such dikes evolves slower compared to a sand dike. The breaching process starts with washing out of small soil particles under flow action. Observations during wave overtopping experiments showed that slit erosion is seldom the dominant cause of dike cover failure (Dutch Ministry of Infrastructure and the Environment 2012). The observations show that firstly, the grass sod on the crest or landward slope is damaged, amongst others due to underpressure fluctuations of the flow that weaken the grass sod. Secondly, the grass sod is pulled out when the roots are exposed to the flow due to overtopping waves (Oumeraci et al. 2005; Quang and Oumeraci 2012). Eventually, the grass sod will fail. Erosion of the underlying clay layer continues, and finally, the core of the dike is washed out. This induces steepening of the slope in time and gradually evolves into a head cut (Zhu 2006).
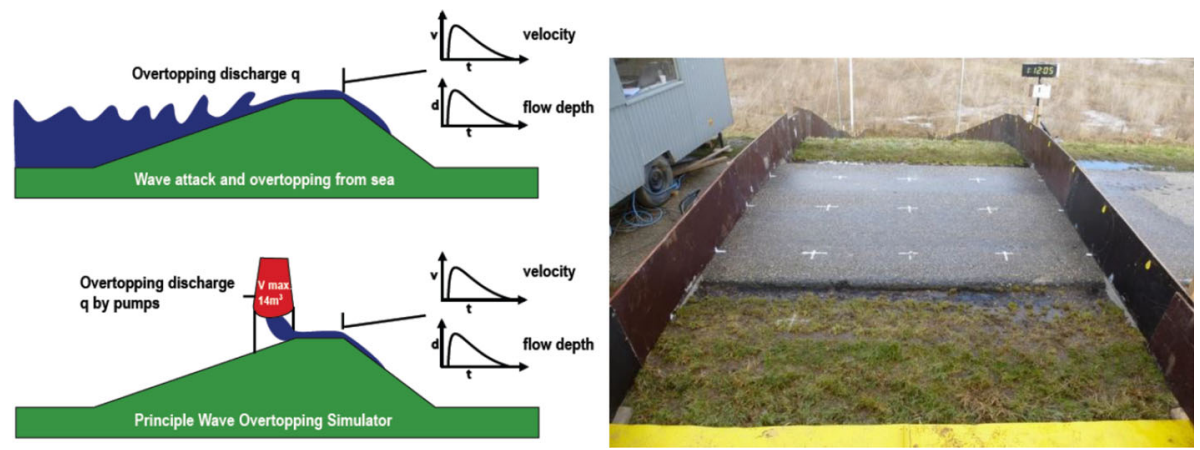

Fig. 1 Principles of the wave overtopping simulator (from Van der Meer et al. 2009) and test section in Millingen aan de Rijn during the erosion experiment (from Bakker et al. 2013) 
Van der Meer et al. (2010) showed that it is difficult to determine whether a grassed slope has start of damage. They use the following damage criteria: (1) first damage, (2) various damaged locations and finally (3) failure (Van der Meer et al. 2010). In this paper we assume that first damage of the grass sod is present when scour is computed after an overtopping event. When scour is predicted at multiple locations, we assume that this represents the second failure criteria as suggested by Van der Meer et al. (2010). Finally, failure occurs when the erosion depth is larger than $10 \mathrm{~cm}$ corresponding with the depth of the grass sod. Because dike erosion is accelerated on the location of first damage, the erosion onset location is essential for further dike breach process. After the core is exposed, which happens at typical erosion depths of $0.5 \mathrm{~m}$, the breaching process leads to fast degradation of the dike. Therefore, we focus on the first and second stage of this breaching process, which is referred to as the start or onset of erosion in this study.

For a dike that consists of one cover material, erosion will probably start to occur close to the toe of the dike, since high flow velocity occurs due to gravitational acceleration (Oumeraci et al. 2005). The overtopping wave gains energy along the slope, which increases the bed shear stress. At the toe the slope changes, resulting in high impact and high bed shear stresses and consequently in jet erosion. Erosion near the toe was also observed during experiments performed with the wave overtopping simulator (WOS), which is a device that generates irregular waves (Van der Meer et al. 2009). It is expected that the erosion pattern changes if a transition of covering materials along the dike profile exists, such as a grass-covered dike with an asphalt road section on top of the crest. Morris (2012) states that transitions in geometry and roughness result in a change in turbulence of the overtopping tongue. This is in agreement with the work of Nezu and Nakagawa (1991) and Nezu and Tominaga (1994) who found that that the velocity profile above a rough bed can be split into two parts, namely into a boundary layer which develops close to the bed and a core region in the upper part of the flow. In the boundary layer a great deformation of the velocity profile was observed caused by a change in the bed roughness. This change in velocity profile was much less significant in the upper part of the stream. Besides, Nezu and Nakagawa (1995) found that the turbulence is stronger for the rising stage than for the falling stage of a discharge wave, suggesting that erosion will most probably be caused by the front edge of the overtopping wave. Not only literature suggests that the erosion processes will change in case of a change in bed roughness, but also experiments performed with the WOS showed that transitions between the soft cover layer of clay and grass with hard structures are weak spots of the revetment and vulnerable to erosion (Steendam et al. 2014).

A lot of research has been done in which models or simplified formulas for wave overtopping and resulting erosion are developed. Schüttrumpf and Oumeraci (2005) derived a set of prediction formulas for wave overtopping velocities and layer thicknesses based on experimental and theoretical investigations. However, no translation towards erosion was made and the set of formulas was derived from a one-dimensional model. Dean et al. (2010) developed a method in which erosion development was computed based on the time-varying characteristics of the intermittent overtopping waves. They showed the importance of time dependency in the computation of scour depths. Tingsanchali and Chinnarasri (2001) have set up a one-dimensional numerical model for dam failure due to flow overtopping. They used the MacCormack explicit finite difference scheme to solve the 1D equations of continuity and momentum for unsteady varied flow over steep bed slopes. The models in the studied literature are all capable of predicting wave overtopping conditions and/or resulting erosion processes under different wave conditions. However, they all assume a homogeneous dike cover, while transitions in bed roughness may have a 
significant effect on the erosion process and location of erosion onset. Additionally, the methods were based on relatively simplified one-dimensional models. A more detailed two-dimensional model is desired to get a good representation of the complex processes of erosion onset on a irregular dike profile with different roughness covers during wave overtopping.

Using a model to study the effects of covering material transitions on erosion onset is convenient, since many different situations can be simulated relatively fast at low costs. It is preferred to have a model in which the boundary conditions can be adapted easily to enable investigation of the effect of constructions of different sizes and materials on erosion onset. Therefore, the objective of the present study is to develop a numerical model to quantify the influence of a road structure on the erosion onset of a grass-covered dike due to wave overtopping. This paper studies the differences in erosion rates for dikes with and without a road structure located on the dike crest. The model developed in this study is innovative since the model is capable of solving both the hydrodynamic conditions during wave overtopping and resulting erosion onset with high detail, while mostly these two aspects are studied separately.

The outline of this paper is as follows. Firstly, the data used for validation are presented. In Sect. 3, the coupled hydrodynamic-erosion model is described, followed by the validation (Sect. 4) and the application to three cases to study the effects of the road structure (Sect. 5). Section 6 contains the discussion, and the paper ends with the main conclusions.

\section{Validation data}

Data from two full-scale wave overtopping experiments are used to validate the modelled hydrodynamics and erosion onset separately. The experiments were carried out using the wave overtopping simulator (WOS) (Steendam et al. 2014). The WOS consists of a mobile tank to store water (Fig. 1). The simulator releases various overtopping volumes following a stochastic random distribution to simulate a realistic overtopping event (Van der Meer et al. 2009). The released discharge is such that the hydrodynamic conditions (e.g. flow velocity, turbulence, thickness of the overtopping tongue) of each overtopping volume correspond with the expected conditions during a flood event (Van der Meer et al. 2009). The number of overtopping waves and their volumes depend on the representative wave conditions and the geometry of the riverside slope of the dike (i.e. a gentler outer slope will lead to a higher number of overtopping waves).

Two wave overtopping experiments (i.e. a hydraulic experiment and an erosion experiment) were performed in Millingen aan de Rijn on a dike with an asphalt road at the crest (Fig. 2). The experiments were conducted for a significant wave height and period of $1.0 \mathrm{~m}$ and $4 \mathrm{~s}$, respectively, and a slope of 1:3 on both riverside and landside (Bakker et al. 2013). These conditions correspond with the characteristics of a typical Dutch river dike (Van der Meer et al. 2010).

\subsection{Hydraulic experiment}

The hydraulic experiment and the erosion experiment had different test sections and test set-ups. The hydraulic experiment was performed to measure near-bed velocities and water depths in time for eight locations along the landward side of the dike. The landside transition gap from the asphalt section to the grass cover was covered with a shelf. 


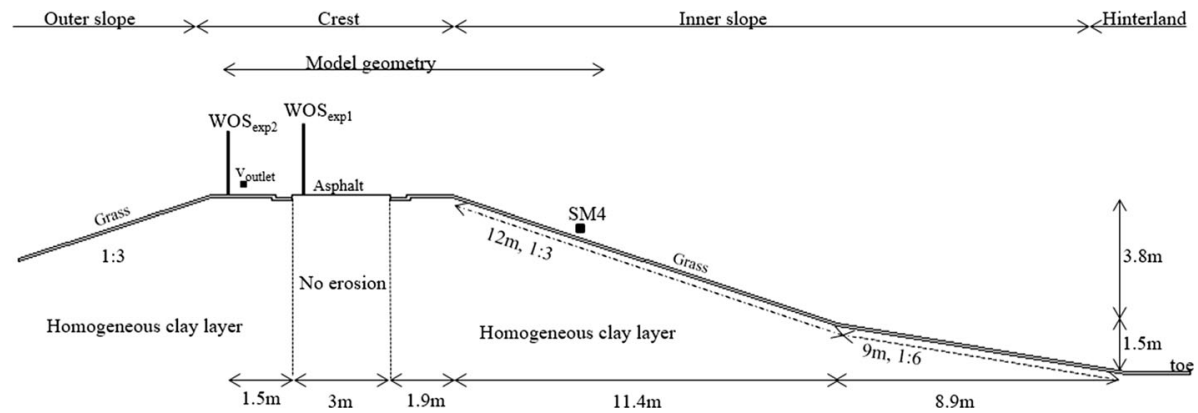

Fig. 2 Overview geometry dike profile Millingen aan de Rijn for both experiments. WOS $\exp 1_{1}$ and WOS exp2 indicate the locations of the wave overtopping simulator, $v_{\text {outlet }}$ the location of the simulator outlet during the erosion experiment, and SM4 the location of the validation data measurements for the hydraulic experiment

Geotextile was located from the simulator outlet till circa $1 \mathrm{~m}$ before the landside crest line covering the damaged road shoulders. This shelf and geotextile resulted in a smooth dike profile. For this reason only test location SM4 is used for validation (Fig. 2), since it is expected that the hydraulic conditions along the slope are not affected by the geotextile located at the crest. During the experiment, individual waves with a fixed volume $(0.40$, $1.00,1.50$ and $2.50 \mathrm{~m}^{3} / \mathrm{m}$ ) were released by the WOS, which was located at the road section $\left(\right.$ WOS $_{\text {exp } 1}$ in Fig. 2). The water depths were measured by 'surf board' devices, and the near-bed flow velocities by paddle wheels placed on the dike surface (Bakker et al. 2013). The hydraulic experiment is used for validation of the hydrodynamic model.

\subsection{Erosion experiment}

The erosion experiment was performed to measure erosion development of the dike profile during wave overtopping using 3D laser scanning at six intervals of $1 \mathrm{~h}$. During the erosion test, the WOS was located $1.5 \mathrm{~m}$ riverward from the edge of the asphalt pavement at the

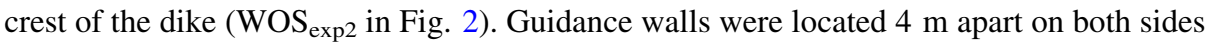
of the test section. The overtopping waves were randomly released following a Weibull distribution with a constant shape factor of 0.75 and a scale factor dependent on the average wave overtopping, mean wave period and the probability of overtopping (Hughes et al. 2012; Steendam et al. 2012). Five storm events with an average overtopping

Table 1 Test set-up of erosion experiment performed in Millingen aan de Rijn

\begin{tabular}{lllll}
\hline $\begin{array}{l}\text { Discharge } \\
\left(\mathrm{m}^{3} / \mathrm{s} / \mathrm{m}\right)\end{array}$ & $\begin{array}{l}\text { Duration of } \\
\text { storm }(\mathrm{h})\end{array}$ & $\begin{array}{l}\text { Accelerated }(+) / \\
\text { decelerated }(-)\end{array}$ & $\begin{array}{l}\text { Accelerated/decelerated } \\
\text { test duration }(\mathrm{h})\end{array}$ & $\begin{array}{l}\text { Interval of laser scan } \\
\text { measurement }(\mathrm{h})\end{array}$ \\
\hline 0.001 & 6 & $+5 x$ & 1.2 & - \\
0.010 & 6 & - & 6 & 2 \\
0.050 & 6 & - & 6 & 1 \\
0.100 & 6 & $-1.25 x$ & 7.5 & 1 \\
0.200 & 6 & $-2 x$ & 12 & 4 \\
\hline
\end{tabular}


discharge were simulated, namely $0.001,0.01,0.05,0.10$ and $0.20 \mathrm{~m}^{3} / \mathrm{s} / \mathrm{m}$. Each discharge was released representing a 6-h storm. However, depending on the inflow capacity of the WOS, the tests were executed accelerated or decelerated (Table 1). This means that the released waves followed up quicker or slower than would be the case in a real storm event. The experiments were carried out consecutively.

Scans were made with the use of a 3D laser scanner to measure the spatial distribution and depth of the scour caused by the overtopping waves. The initial dike profile was scanned, and after several hours, depending on the discharge released, the dike profile was rescanned (Bakker et al. 2013) (Table 1).

During the erosion experiment, the largest scour was observed at the landside transition between the asphalt layer and grass sod, and little scour was observed along the slope and at the dike toe (Bakker et al. 2013). At the road-grass transitions, holes were present on both sides of the asphalt pavement due to the damage by cars (Fig. 3). On the riverside this transition gap showed a little effect on the erosion development (Bakker et al. 2013), while on the landside the overtopping wave hit the bare clay layer directly (Fig. 3). Therefore, significant erosion is expected at the landside of the road section.

\subsection{Hydraulic validation data}

We used the $0.40,1.00$ and $1.50 \mathrm{~m}^{3} / \mathrm{m}$ wave volumes for validation, because reliable validation data of these volumes were available (see Sect. 2.1). Each wave volume was released, and the maximum velocities and water depths were measured two times. Table 2 shows the measured maximum near-bed velocities and maximum water depths at test location SM4 for three wave volumes (Fig. 2).

In addition to these hydraulic field measurements, hydraulic measurements were taken separately at the simulator outlet (Fig. 4) during calibration of the WOS in an earlier experiment. The waves were measured on a horizontal plate three metres from the simulator valve such that the waves were flowing in horizontal direction. The maximum flow velocities occur at the WOS outlet, since the overtopping wave is not yet slowed down by the roughness of the grass cover. Velocities and depths of volumes ranging from 0.015 to

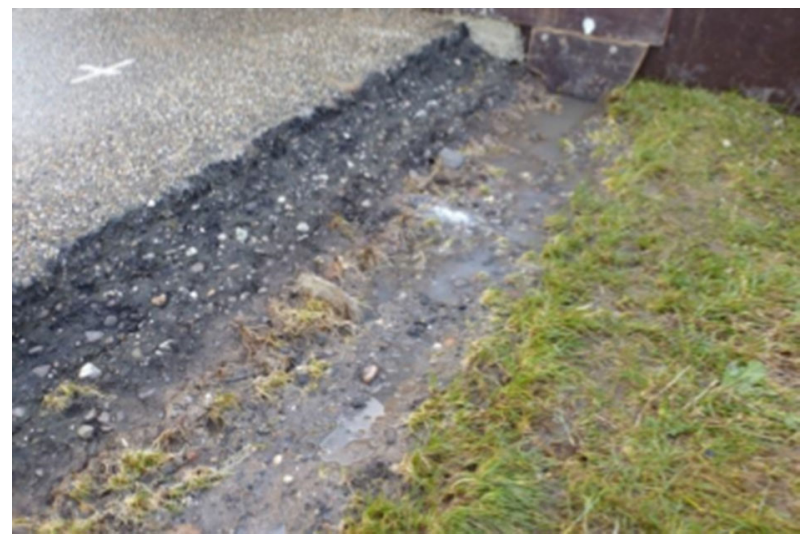

Fig. 3 Damaged transition present before the experiment in Millingen aan de Rijn started (Bakker et al. 2013). The damaged grass sod highly influenced erosion development on the landside transition 
Table 2 Hydraulic validation data at test location SM4. $v_{\mathrm{SM} 4}$ denotes the maximum near-bed velocity and $h_{\mathrm{SM} 4}$ represents the maximum water depth, measured using the surf board

\begin{tabular}{lll}
\hline Volume $\left(\mathrm{m}^{3} / \mathrm{m}\right)$ & $v_{\mathrm{SM} 4}$ measured $(\mathrm{m} / \mathrm{s})$ & $h_{\mathrm{SM} 4}$ measured $(\mathrm{m})$ \\
\hline 0.40 & 4.30 & 0.02 \\
0.40 & 4.45 & 0.02 \\
1.00 & 5.14 & 0.06 \\
1.00 & 5.12 & 0.06 \\
1.50 & 5.55 & 0.09 \\
1.50 & 5.68 & 0.10 \\
\hline
\end{tabular}

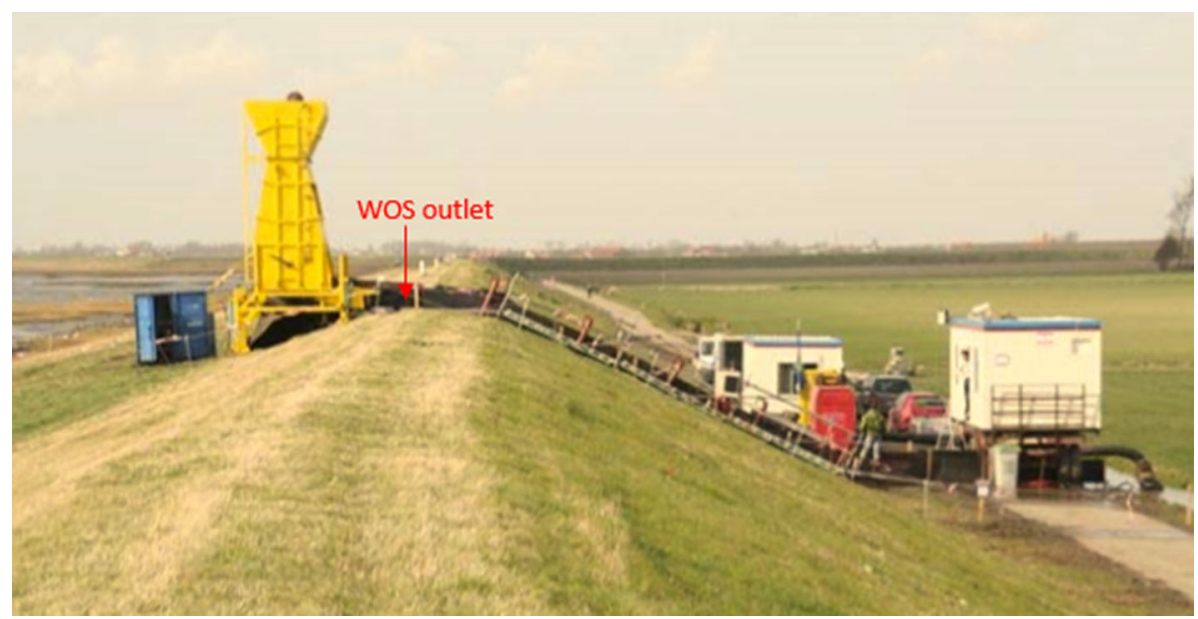

Fig. 4 Overview of the test set-up of the hydraulic measurements (from Dutch Ministry of Infrastructure and the Environment 2012). The measurements will be used to validate the hydrodynamic conditions at the simulator outlet of the hydrodynamic model

Table 3 Measured hydrodynamic conditions at the simulator outlet (ComCoast 2007). $v_{\text {outlet }}$ denotes the maximum near-bed velocity at the simulator outlet, $h_{\text {outlet }}$ the maximum water height, and $T_{\text {ovt }}$ the overtopping time of the wave

\begin{tabular}{llll}
\hline Volume $\left(\mathrm{m}^{3} / \mathrm{m}\right)$ & $v_{\text {outlet }}$ measured $(\mathrm{m} / \mathrm{s})$ & $h_{\text {outlet }}$ measured $(\mathrm{m})$ & $T_{\text {ovt }}$ measured $(\mathrm{s})$ \\
\hline 0.15 & 2.95 & 0.10 & 1.48 \\
0.40 & 3.43 & 0.13 & 2.05 \\
0.70 & 4.10 & 0.15 & 2.38 \\
1.00 & 4.62 & 0.18 & 2.78 \\
1.50 & 4.84 & 0.20 & 3.40 \\
\hline
\end{tabular}

$2.5 \mathrm{~m}^{3} / \mathrm{m}$ at the simulator outlet ( $v_{\text {outlet, }}, h_{\text {outlet }}$ ) were measured (Table 3 ) in the ComCoast project (ComCoast 2007). The values in Table 3 correspond to averaged values of several numbers of tests. These values are used to validate the modelled depth and velocity at the outflow point of the WOS. 


\subsection{Erosion validation data}

The dike profiles used for validation are constructed, based on the point cloud from the 3D laser scans (see Sect. 2.2). The profile for validation was derived from the laser scan data located within a certain width window along the centre line of the test section. These data scan points were interpolated to create a cross-sectional profile using linear interpolation.

Significant erosion started to occur during the test with a discharge of $0.05 \mathrm{~m}^{3} / \mathrm{s} / \mathrm{m}$ (Bakker et al. 2013). Although some scour was observed during the tests with lower overtopping discharges, the dike profile measured at the start of the $0.05 \mathrm{~m} 3 / \mathrm{s} / \mathrm{m}$ test is used as initial condition in the model simulation.

\section{Coupled hydrodynamic-erosion model}

The erosion onset due to wave overtopping is computed with a coupled hydrodynamicerosion model (Fig. 5). This model consists of a CFD simulation (the hydrodynamic model) to compute the time-variant bed shear stresses and an erosion model, which is used to compute the scour depths based on these bed shear stresses. The hydrodynamic and erosion models are described in detail in Sects. 3.1 and 3.2.

The study focuses on the crest of the dike, and therefore, the model domain only includes the crest and upper part of the inner slope (Fig. 2). The eroded dike profiles are obtained by subtracting the local scour depth from the initial dike profile. After adapting the dike profile, the CFD simulation is run again to compute the bed shear stresses for the updated dike profile. It is assumed that the grass cover is completely eroded when the erosion depth is larger than $10 \mathrm{~cm}$ (Hoffmans 2012). This value is justified by the work of Le et al. (2017) in which they state that between 60 and $90 \%$ of the total number of grass roots are present in the first $10 \mathrm{~cm}$ under the soil surface. The roughness and erodibility at the locations where the grass cover is completely eroded are then adapted to a value that corresponds with clay. The erosion model assumes a grass cover of $10 \mathrm{~cm}$ with equal strength along the dike profile, i.e. no damage is present. In reality, three transitions exist, namely the riverside road shoulder (grass to asphalt), the landside road shoulder and the brink point towards the landside slope. The exact thickness of the grass cover was not available at these transitions, and for simplicity, we assumed an undamaged grass cover of $10 \mathrm{~cm}$ thickness. This assumption will be evaluated in the discussion.

The $0.05 \mathrm{~m}^{3} / \mathrm{s} / \mathrm{m}$ test with a duration of $6 \mathrm{~h}$ consisted of approximately 3000 random waves. It is not required to replicate each volume individually (Van der Meer et al. 2006). Besides, the scour depth that results due to a single overtopping wave is relatively small and therefore it is not efficient to simulate each overtopping wave with an updated dike

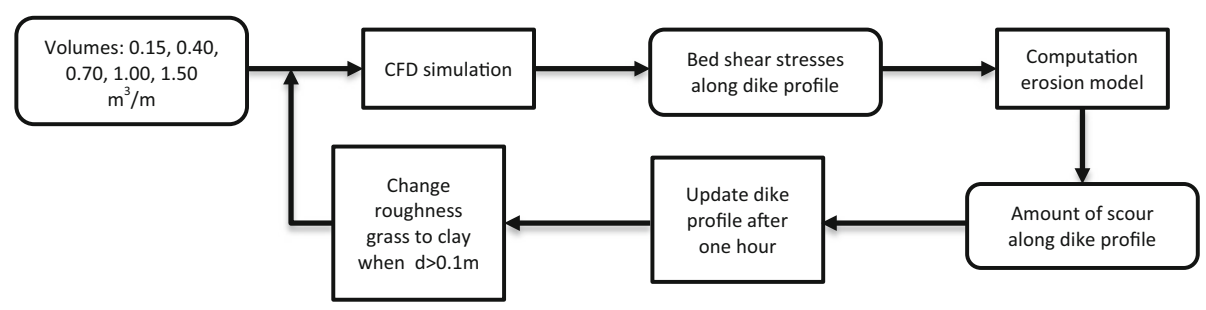

Fig. 5 Steps of the coupled hydrodynamic-erosion model 
profile. For this reason, the random overtopping waves released during the erosion experiment were transformed to a fixed number of overtopping waves, while ensuring that the total volume that overtops equals on average. We approximate the experimentally released waves by discretizing the distribution of overtopping volumes into five representative volumes (Fig. 6). In this approximation the average overtopping discharges are maintained.

The dike profile is updated after 60 min of field testing for a discharge of $0.05 \mathrm{~m}^{3} / \mathrm{s} / \mathrm{m}$, which corresponds to roughly 500 waves. Updating is performed after $1 \mathrm{~h}$ since erosion validation data are available at these moments. The updated dike profile after an overtopping duration of $1 \mathrm{~h}$ is computed by accumulating the scour depths caused by the single overtopping wave volumes within this duration for every location along the profile and subtracting this from the original profile. After updating, the CFD model is run again for the updated dike profile. This approach is similar to the often used morphological factor in morphological modelling (Roelvink 2006). The coupled hydrodynamic-erosion model is developed to get insight into erosion onset, since the location of first damage is essential for further dike breach processes. Therefore, the erosion test with a discharge of $0.05 \mathrm{~m}^{3} / \mathrm{s} /$ $\mathrm{m}$ is only simulated up till $3 \mathrm{~h}$, after which an erosion depth of approximately $7.2 \mathrm{~cm}$ was observed.

The above-described schematized wave distribution is used to validate the model (Sect. 4), representing a storm with an average discharge of $0.05 \mathrm{~m}^{3} / \mathrm{s} / \mathrm{m}$. The following five overtopping volumes are present in the schematized distribution: 0.15, 0.40, 0.70, 1.00 and $1.50 \mathrm{~m}^{3} / \mathrm{m}$ (Fig. 6). After validation of the coupled hydrodynamic-erosion model, a case study is performed in which the effect of roughness on erosion onset is studied (Sect. 5). To perform the case study we only use the maximum wave volume $\left(1.5 \mathrm{~m}^{3} / \mathrm{m}\right)$ present in the schematized distribution since the smaller volumes did not show significant erosion. Besides, the effect of roughness on erosion onset is independent of a storm condition.

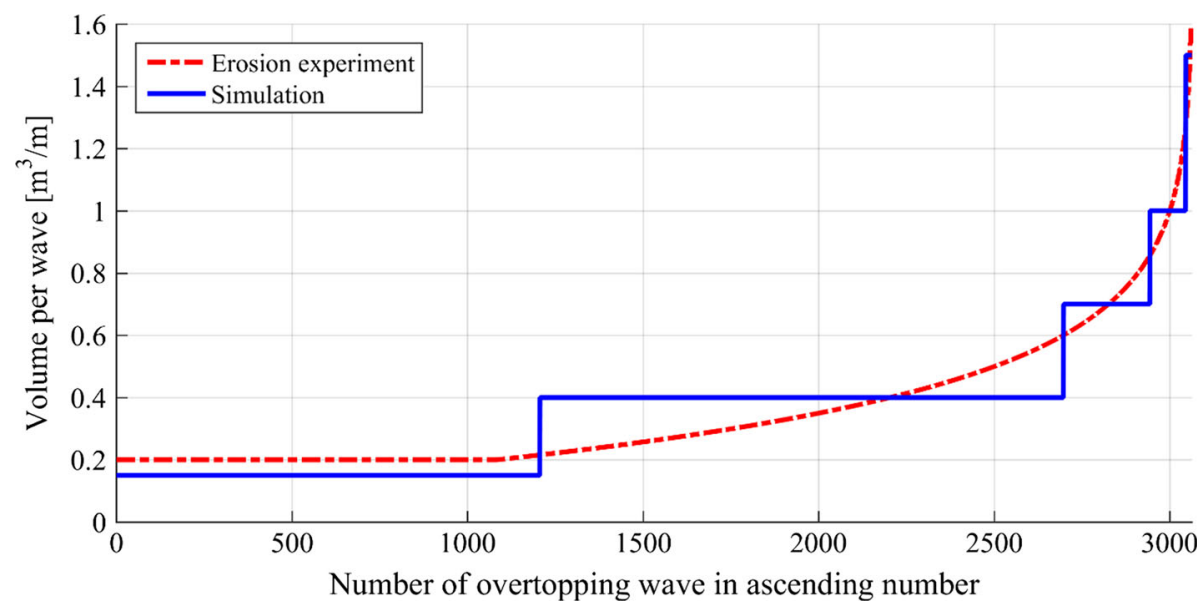

Fig. 6 Released overtopping volumes during the experiment with an overtopping discharge of $0.05 \mathrm{~m}^{3} / \mathrm{s} / \mathrm{m}$ and simulated overtopping volumes to validate the erosion model 


\subsection{Hydrodynamic model}

The hydrodynamic CFD simulation is performed with COMSOL Multiphysics (COMSOL bv 2012) using a two-dimensional (2DV) unsteady model. A two-dimensional, two-phase model was developed since wave overtopping on grass-covered dikes is highly aerated and turbulent. Therefore, modelling grass erosion under extreme flow conditions as a function of the bed shear stress based on the depth-averaged parameters as applied for ordinary open-channel flows appears to be underestimated (Quang and Oumeraci 2012). The hydrodynamic CFD model solves the Reynolds-averaged Navier-Stokes (RANS) equations with a $k-\varepsilon$ turbulence model. Schüttrumpf and Oumeraci (2005) showed the applicability of the two-dimensional continuity and momentum equation for an incompressible flow for computation of the hydrodynamic conditions during wave overtopping.

The RANS equation is presented in formula (1), and the general equations of the $k-\varepsilon$ turbulence model are provided in formulae (2) till (4) (Spalding and Launder 1974). The two-phase flow method is used to track the interface between water and air. A threshold was used to distinguish between the overtopping wave and air. It was assumed that if the volume fraction of water was larger than 0.98 , i.e. $98 \%$ of the grid cell consists of water and $2 \%$ consists of air, the grid cell was treated as being part of the overtopping wave. The 98\% volume fraction was determined during calibration of the model and used to determine the water surface which is therefore not fixed during the simulation.

$$
\rho \frac{\partial u}{\partial t}-\left[\left(\mu+\mu_{\mathrm{T}}\right)\left(\nabla u+(\nabla u)^{\mathrm{T}}\right)\right]+\rho(u \times \nabla) u+\nabla p=F,
$$

where $\rho$ represents the density of water $\left(\mathrm{kg} / \mathrm{m}^{3}\right), u$ the velocity field $(\mathrm{m} / \mathrm{s}), \mu$ the shear rate viscosity $(\mathrm{Pa} * \mathrm{~s}), \mu_{\mathrm{T}}$ the turbulent viscosity $\left[\left(\mathrm{N} / \mathrm{m}^{2}\right) * \mathrm{~s}\right], p$ the pressure $\left(\mathrm{N} / \mathrm{m}^{2}\right)$, and $F$ the volume force field $\left(\mathrm{N} / \mathrm{m}^{3}\right)$.

$$
\begin{gathered}
\frac{\partial \epsilon}{\partial t}=\frac{1}{\rho} \frac{\partial}{\partial x_{\mathrm{k}}}\left[\frac{\mu_{\mathrm{t}}}{\sigma_{\epsilon}} \frac{\partial \epsilon}{\partial x_{\mathrm{k}}}\right]+\frac{C_{1} \mu_{\mathrm{t}}}{\rho} \frac{\epsilon}{k}\left(\frac{\partial U_{\mathrm{i}}}{\partial x_{\mathrm{k}}}+\frac{\partial U_{\mathrm{k}}}{\partial x_{\mathrm{i}}}\right) \frac{\partial U_{\mathrm{i}}}{\partial x_{\mathrm{k}}}-C_{2} \frac{\epsilon^{2}}{k} \\
\frac{\partial k}{\partial t}=\frac{1}{\rho} \frac{\partial}{\partial x_{\mathrm{k}}}\left[\frac{\mu_{\mathrm{t}}}{\sigma_{\mathrm{k}}} \frac{\partial k}{\partial x_{\mathrm{k}}}\right]+\frac{\mu_{\mathrm{t}}}{\rho}\left(\frac{\partial U_{\mathrm{i}}}{\partial x_{\mathrm{k}}}+\frac{\partial U_{\mathrm{k}}}{\partial x_{\mathrm{i}}}\right) \frac{\partial U_{\mathrm{i}}}{\partial x_{\mathrm{k}}}-\epsilon \\
\mu_{\mathrm{t}}=\rho C_{\mu} \frac{k^{2}}{\epsilon},
\end{gathered}
$$

where $\epsilon$ represents the rate of dissipation of turbulence energy $\left(\mathrm{m}^{2} / \mathrm{s}^{3}\right), k$ the turbulence kinetic energy $\left(\mathrm{m}^{2} / \mathrm{s}^{2}\right), \sigma$ the effective turbulent Prandtl number $(-)$, and $U$ the mean velocity component $(\mathrm{m} / \mathrm{s})$. The values of dimensionless constants $C_{1}=1.44, C_{2}=1.92$, $C_{\mu}=0.09, \sigma_{\varepsilon}=1.3$ and $\sigma_{\mathrm{k}}=1$ are taken from Launder et al. (1972).

The WOS is included in the model domain to explicitly simulate the conversion from overtopping volumes to the velocity field (Fig. 7). Atmospheric pressure is included as a pressure distribution along the model domain. Wall functions with a no-slip condition at the bed as suggested by Schüttrumpf and Oumeraci (2005) are applied to account for the roughness of the different materials. The roughness of the grass and asphalt sections were taken from Van Hoven et al. (2013), and the roughness of clay is based on the normal value given by Chow (1959) (Table 4). The roughness of steel is determined by calibration on the maximum flow velocities at the simulator outlet and corresponds with the maximum value given by Chow (1959). Inlet and outlets with a pressure boundary condition are 


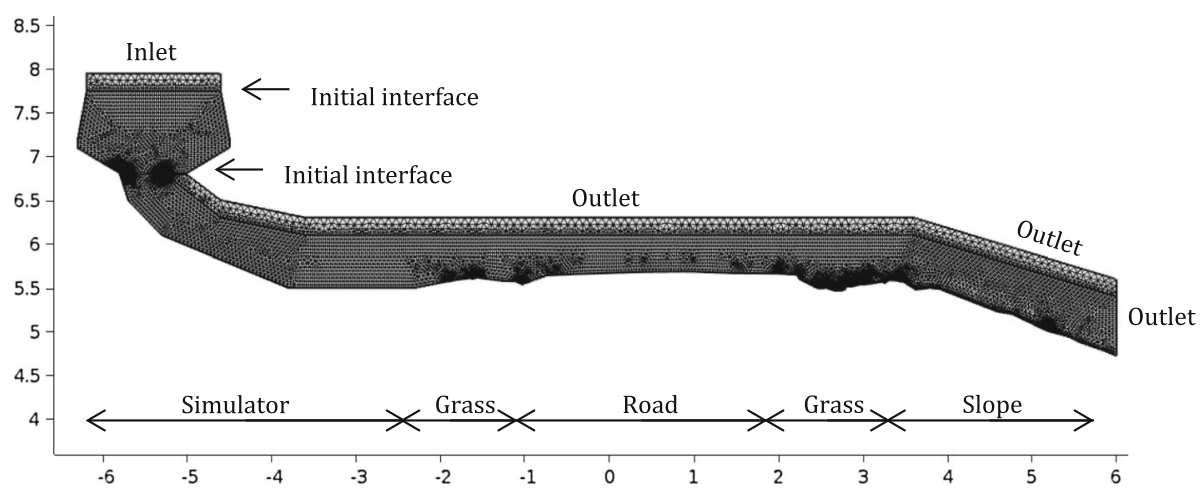

Fig. 7 Mesh and boundary conditions of the hydrodynamic model

Table 4 Roughness of the different materials used in the hydrodynamic model

\begin{tabular}{lll}
\hline Material & Nikuradse roughness height $(\mathrm{m})$ & References \\
\hline Grass & $6.8 \times 10^{-2}$ & Van Hoven et al. (2013) \\
Clay & $2.1 \times 10^{-3}$ & Chow (1959) \\
Asphalt & $4.7 \times 10^{-3}$ & Van Hoven et al. (2013) \\
Steel & $6.8 \times 10^{-3}$ & Chow (1959) \\
\hline
\end{tabular}

located at the remaining model boundaries, in which air enters the model through the inlet, and water and air are capable of leaving the model domain by the outlets (Fig. 7).

The COMSOL solver uses the finite element method on a triangular mesh grid to solve the governing equations. The element size decreases vertically to obtain a high accuracy near the surface of the dike profile, where high detail is required to accurately compute the friction velocities, which are an output of the RANS $\mathrm{k}-\varepsilon$ turbulence model. These friction velocities are then used to compute the bed shear stresses along the dike profile with the following formula:

$$
\tau_{\mathrm{b}}=u^{* 2} \times \rho_{\mathrm{w}},
$$

where $\tau_{b}$ represents the bed shear stress $\left(\mathrm{N} / \mathrm{m}^{3}\right), u^{*}$ the friction velocity $(\mathrm{m} / \mathrm{s})$, and $\rho_{\mathrm{w}}$ the density of water $\left(\mathrm{kg} / \mathrm{m}^{3}\right)$.

Along the landside slope of the dike profile, the velocities increase resulting in lower water depths. Therefore, a finer mesh is needed to accurately capture the vertical velocity distribution profile on the steep slope. To provide this, a boundary layer with quadrilateral elements is defined along the landward dike slope that consisted of three cells of $2.3 \mathrm{~mm}$ height each. Quadrilateral mesh elements capture flow conditions more accurately along the steep slope, because the flow is parallel to the bottom of this slope and almost no changes in normal direction are expected. Additionally, more detail in the road shoulders is needed to be able to capture the change in hydrodynamics due to the road section precisely. The final mesh consists of 13,030 domain elements and 926 boundary elements (Fig. 7). 


\subsection{Erosion model}

Erosion development of a complex system as a grass covered profile with underneath a clay layer is largely unexplored and has many unknowns. For this reason we take assumptions (based on literature and field experiments) such that an erosion model can be developed. This erosion model is a first attempt to identify the locations of erosion onset for a grass-covered dike profile with a road on top. In the discussion (Sect. 6) we will provide a sensitivity analysis on the uncertain parameters mentioned in this section.

The erosion model is based on the turf-element model presented in Hoffmans (2012), which is the most detailed method available at the moment to describe erosion of grass and clay. This model assumes that the erosion process is gradual slit erosion, similar to the erosion of sand, while in reality the erosion process of a grass sod is much more complex (e.g. underpressure fluctuations, folding of the grass sod, breaking of the roots, washing out of clay particles). Modelling these detailed processes is not feasible. Therefore, we adopt the simplified slit erosion model, which proves able to model the larger-scale trends and order of magnitude of the scour quite well. This assumption is discussed in Sect. 6.

In the turf-element model, erosion depths are computed as a function of depth-averaged velocity (Hoffmans 2012):

$$
y_{\mathrm{m}}=\frac{\left(\omega U_{0}-U_{\mathrm{c}}\right)^{2} \times t_{\mathrm{wave}}}{E_{\text {soil }}},
$$

where $y_{\mathrm{m}}$ represents the amount of scour due to a single overtopping wave $(\mathrm{m}), U_{0}$ the depth-averaged flow velocity $(\mathrm{m} / \mathrm{s}), U_{\mathrm{c}}$ the critical depth-averaged velocity $(\mathrm{m} / \mathrm{s}), t_{\text {wave }}$ the overtopping time, $E_{\text {soil }}$ the soil erosion parameter $(\mathrm{m} / \mathrm{s})$, and $\omega$ the turbulence coefficient $(-)$. The value of the soil parameter $E_{\text {soil }}$ depends on the qualities of both grass and clay and was calibrated using a prototype experiment (Hoffmans et al. 2008). The turbulence coefficient $\omega$ is a function of the turbulence intensity and is related to the friction of the bed (Hoffmans et al. 2008). It accounts for the turbulence generated by surface friction and can be given with the following formula (Hoffmans 2012):

$$
\omega=1.5+5 r_{0},
$$

where $r_{0}$ represents the depth-averaged relative turbulence intensity (-). The turbulence coefficient used in this study is based on the measured depth-averaged relative turbulence intensities during the field experiment in Millingen aan de Rijn. Along the crest a turbulence intensity of $0.17(-)$ is assumed and along the slope a value of $0.10(-)$.

The turf-element model computes the amount of erosion due to a single overtopping wave. Considering all waves during a storm the term $\left(\omega U_{0}-U_{\mathrm{c}}\right)^{2}$ in formula (6) can be replaced by $\sum\left(0.7 \omega U_{\max }-U_{\mathrm{c}}\right)^{2}$ (Hoffmans et al. 2008), where $U_{\max }$ represents the maximum flow velocity per overtopping event $(\mathrm{m} / \mathrm{s})$.

The turf-element model is only applicable for an erosion depth smaller than 0.1 metres. Valk (2009) extended this model for greater depths, and therefore, it is not restricted to scour of the grass cover only. This was done by implementing a depth dependency factor for the soil strength. The equation of Hoffmans (2012) can also be adapted to a bed shear stress-dependent function, resulting in the following formula: 


$$
y_{\mathrm{m}}=\frac{\left(\omega^{2} \tau_{0}-\tau_{\mathrm{c}}(d)\right) \times t_{\mathrm{wave}}}{E_{\mathrm{soil}}(d)},
$$

where $\tau_{0}$ and $\tau_{\mathrm{c}}$ represent the bed shear stress $\left(\mathrm{N} / \mathrm{m}^{3}\right)$ and critical bed shear stress $\left(\mathrm{N} / \mathrm{m}^{3}\right)$, respectively. The critical bed shear stress and soil parameter are now both a function of depth.

In this study the bed shear stress is used as a loading parameter, while lift forces caused by the pressure fluctuations perpendicular to the grass cover are the driving forces of erosion of the grass cover (Hoffmans 2012). Hoffmans (2012) states that soils can easily withstand pressure forces and that the critical soil pressure is significantly higher than the critical tensile stress. In his work he found a relation between the critical bed shear stress and the tensile strength. This relation is used in this study such that the bed shear stress can be used as loading parameter of the erosion model.

Dean et al. (2010) showed the importance of including overtopping duration and the effect of using intermittent wave overtopping for the computation of dike erosion. The method of Dean et al. (2010) was extended by Hughes (2011) to accurately estimate the excess wave volume above a critical bed shear stress threshold for each overtopping wave, in which the cumulative excess work volume is the summation of the erosion contributions of the individual overtopping waves. We combined the methods of Valk (2009), Dean et al. (2010) and Hughes (2011) to adapt the turf-element model presented in Hoffmans (2012) to a time- and depth-dependent erosion model. The erosion model is time dependent since the predicted scour depth due to an overtopping wave is based on the space- and timevarying bed shear stress using a defined time step. The model is depth dependent since the dike profiles are adapted based on computed erosion, and hence also the strength parameters of the clay layer and grass sod are adapted. The resulting erosion model for the scour at a certain location (grid cell) during one time step is given by:

$$
y_{\mathrm{n}}=\frac{\omega^{2}\left(\frac{\tau_{\mathrm{i}}+\tau_{\mathrm{i}+1}}{2}-\tau_{\mathrm{c}}(d)\right) \times \Delta t}{E_{\text {soil }}(d)} \quad \text { if } \quad \tau_{\mathrm{i}}>\tau_{\mathrm{c}},
$$

where $y_{\mathrm{n}}$ represents the amount of scour per time step within a wave $(\mathrm{m}), \tau_{\mathrm{i}}$ the bed shear stress at time step $i$ obtained with the hydrodynamic model $\left(\mathrm{N} / \mathrm{m}^{2}\right)$, and $\Delta t$ the time step (s). Scour only occurs when the bed shear stress $\tau_{\mathrm{i}}$ exceeds the critical bed shear stress $\tau_{\mathrm{c}}$, see formula 9 .

The total scour $(Y)$ during a single wave is computed by a summation of the scour depth per time step:

$$
Y=\sum_{n=1}^{N} y_{\mathrm{n}}
$$

The model assumes a clay and grass strength dependent of depth (d). For this reason, also the critical bed shear stress and soil parameter are a function of depth and can be given with the following formulas (Valk 2009):

$$
\begin{gathered}
\tau_{\mathrm{c}}(d)=\alpha_{\tau} \times\left(\left(\rho_{\mathrm{s}}-\rho_{\mathrm{w}}\right) g d_{\mathrm{a}}+\tau_{\text {total }}(d)\right) \\
E_{\text {soil }} \equiv \frac{v \times U_{\mathrm{c}}(d)^{2}}{10^{-10} \times g^{2} d_{\mathrm{a}}}
\end{gathered}
$$




$$
U_{\mathrm{c}}(d)=\frac{2}{r_{0}} \sqrt{\Delta g d+\frac{\tau_{\text {total }}(d)}{\rho_{\mathrm{w}}}},
$$

where $\alpha_{\tau}$ represents the pressure fluctuation coefficient, being the inverse of the maximum pressure difference and having a value of $1 / 18(-) . d_{\mathrm{a}}$ represents the aggregate diameter. A value of $0.004(\mathrm{~m})$ is used, corresponding with the size of the aggregates, clay particles bounded together by the root system. $v$ represents the kinematic viscosity of water, and $\Delta$ the relative density having a value of $1(-)$ based on a water density of $1000\left(\mathrm{~kg} / \mathrm{m}^{3}\right)$ and a sediment density of $2000\left(\mathrm{~kg} / \mathrm{m}^{3}\right) \cdot \tau_{\text {total }}(d)$ represents the total strength of the soil layer. In this study the strength of the grass cover and clay layer. At the surface the total strength is dominated by the grass cover. We assume that the root density and therefore grass strength decrease exponentially with depth (Le et al. 2017; Sprangers 1999). Besides, we assume that the strength of clay cohesion increases linearly with depth (Fig. 8), resulting in the following formula for the total strength of the soil (Valk 2009):

$$
\tau_{\text {total }}(d)=f \times \tau_{\text {clay }, 0}\left(1+a_{\text {cs }} \times d\right)+\sigma_{\text {roots }, 0} \times \mathrm{e}^{-\beta d},
$$

where $f$ represents the inhomogeneousity factor having a value of $0.21(-)$, and $\tau_{\text {clay }}(d)$ and $\sigma_{\text {roots }}(d)$ the clay cohesion and root tensile strength, respectively, both as a function of depth. At $d=0$ the clay cohesion equals $11,900 \mathrm{~N} / \mathrm{m}^{2}$ and the strength of the grass equals $7760 \mathrm{~N} / \mathrm{m}^{2}$, as was measured during the field experiment. $a_{\mathrm{cs}}$ and $\beta$ represent the coefficient of clay cohesion increase over depth and coefficient of the root strength decrease over depth, respectively. The value of $a_{\mathrm{cs}}$ is determined during the calibration procedure of the erosion model such that the simulated erosion onset during the first hour of testing with an average discharge of $0.5 \mathrm{~m}^{3} / \mathrm{s} / \mathrm{m}$ is close to what was measured in the field. We found a value of $20 \mathrm{~m}^{-1}$ for $a_{\mathrm{cs}} . \beta$ has a value equal to 22.32 (-) and was taken from Valk (2009). The validation of the erosion model should show whether the calibrated and assumed values of $a_{\mathrm{cs}}$ and $\beta$, respectively, result in accurate predictions of the amount of scour along the dike profile (Sect. 4.2).

The strength of the grass and clay layer influences the erosion resistance. A linearly increase in clay cohesion with depth seems physically unrealistic, since it will reach an equilibrium state at a certain depth. This is justified since the model is only valid for

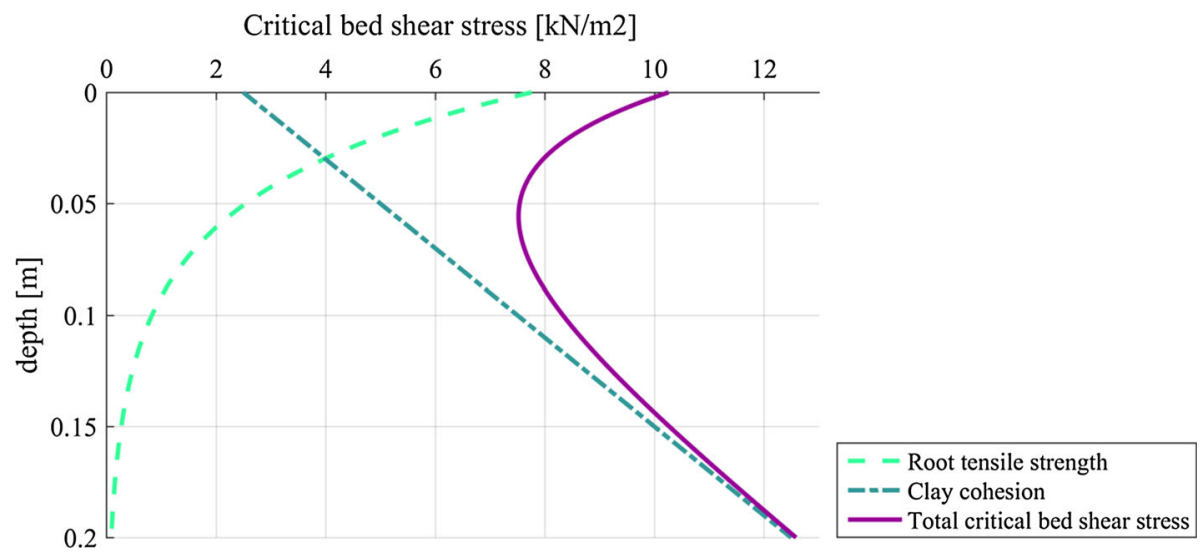

Fig. 8 Visualization of the adopted grass and clay strength in terms of critical bed shear stress as a function of depth 
erosion depths up to circa $0.2 \mathrm{~m}$ for which the increased cohesion is expected. Deeper erosion may lead to a head cut and possibly exposure of the core of the dike. Therefore, the erosion modelling approach is not valid in such circumstances anyway.

The erosion model assumes a grass sod with a depth of $0.1 \mathrm{~m}$ based on the work of Hoffmans (2012). Horizontal variations of the grass strength are neglected. Underneath the grass cover a homogeneous clay core is present, which is the case for most Dutch dikes in the top $0.5 \mathrm{~m}$. Erosion of the foundation underneath the road section is not considered in this paper (Fig. 2). Erosion is computed as slit erosion in this study, and deposition is not included in the model since it is assumed that all eroded particles are transported out of the model domain. This assumption is reasonable given the high flow velocities and field observations only show deposition downstream of the dike toe (which is beyond the model domain).

The coupled hydrodynamic-erosion model computes the erosion depths at every grid cell in the model along the initial dike profile. Subtracting the estimated erosion depths from the initial profile and using a linear interpolation algorithm to create a closed line (profile) from the output location points leads to an updated dike profile.

\section{Model validation results}

\subsection{Validation hydrodynamic model}

In this section the hydrodynamic model is validated. Firstly, the general pattern of the simulated overtopping tongue is compared with the literature. Thereafter, flow velocities, water depths and overtopping times along the dike profile are validated with the use of the experimental data (Sect. 2.3).

Observations from other experiments in the literature show that the maximum water depth of the overtopping wave should appear in the front edge of the overtopping wave and should decrease gradually towards the tail, as was mentioned by Dean et al. (2010), Hughes and Nadal (2009), Schüttrumpf and Oumeraci (2005) and Trung (2014b). The model result (Fig. 9) also shows this pattern with a steep increase in water depth in the front edge and a

Fig. 9 Water depths at simulator outlet for five overtopping waves with different volumes as a function of time

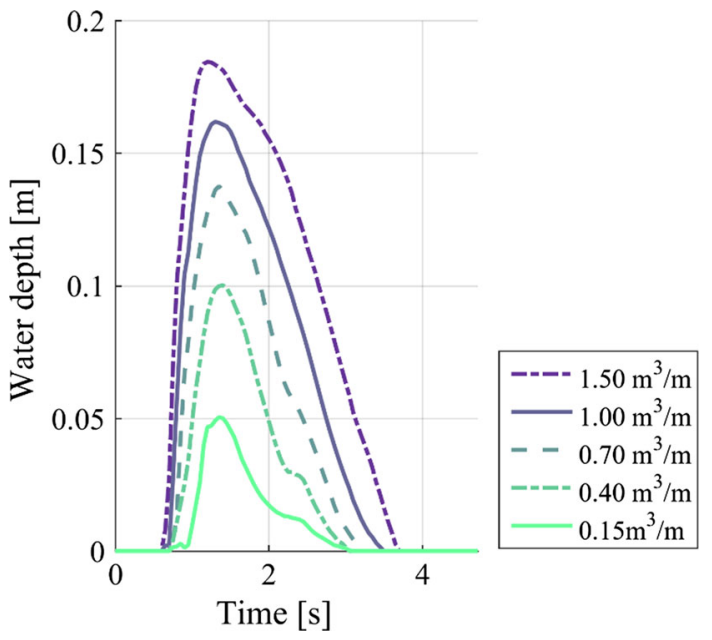


more gradual decrease along the slope. So the hydrodynamic model is able to correctly simulate the evolution of the wave for different volumes.

Van der Meer et al. (2009) mention that during wave overtopping the flow is highly turbulent and the water surface is not smooth. Furthermore, the flow velocities near the bed are lower than at the surface due to bottom friction. Figure 10 shows the flow velocity profile of an overtopping wave with a volume of $1.5 \mathrm{~m}^{3} / \mathrm{m}$ at $t=1.7 \mathrm{~s}$. The profile clearly shows a rough surface corresponding with the high turbulence and air entrapment in the flow. Furthermore, the flow velocities along the bed are lower than at the surface, as expected.

Additionally, Schüttrumpf and Oumeraci (2005) showed that flow velocity and water depth of the overtopping tongue decrease along the dike crest due to elongating of the overtopping tongue. The front moves faster than the back of the tongue. Figure 11 shows that the model is capable of simulating the general pattern of an overtopping wave, namely elongated (deep and fast at the front) and accelerating down the slope.

Table 5 shows the validation results at the simulator outlet. The simulated maximum velocities at the outlet deviate less than $20 \%$ of the measured maximum velocities for all wave volumes. The maximum water depths at the outlet show reasonable agreement with measurements for the large overtopping volumes. However, they are underestimated for the 0.15 and $0.40 \mathrm{~m}^{3} / \mathrm{m}$ volumes, while discrepancies between measured and simulated overtopping times show opposite patterns. So, for the 0.15 and $0.40 \mathrm{~m}^{3} / \mathrm{m}$ volumes the depths are underestimated and consequently the overtopping time is overestimated, showing that the overtopping wave is too stretched. The overestimation of the overtopping time would yield small overestimation of the predicted total bed shear stress during an overtopping wave in the lowest volume simulation. However, this overestimation due to the $0.015 \mathrm{~m}^{3} / \mathrm{m}$ volume probably only has a small effect on the erosion results since bed shear stresses caused by this volume are relatively small compared to the bed shear stresses of the larger overtopping volumes. Additionally, only the overtopping time above the critical bed shear stress affects scour. Therefore, the effect of overestimation of the overtopping time on erosion onset will be limited. The underestimation of the simulated water depths may be caused by the way the water depths were measured during the hydraulic measurements. The measured water depths also included air entrainment. Although the numerical simulation is capable of including air entrapment, the modelled air entrapment may be underestimated, leading to lower simulated maximum water depths of the overtopping waves. In such highly turbulent streams, air entrapment is complicated

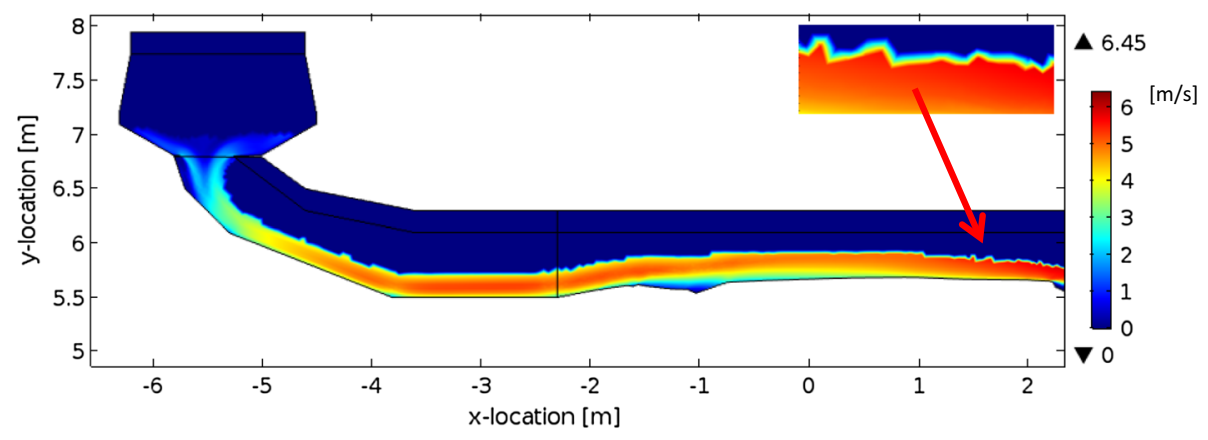

Fig. 10 Flow velocities $(\mathrm{m} / \mathrm{s})$ of the overtopping tongue at time $t=1.7 \mathrm{~s}$ 

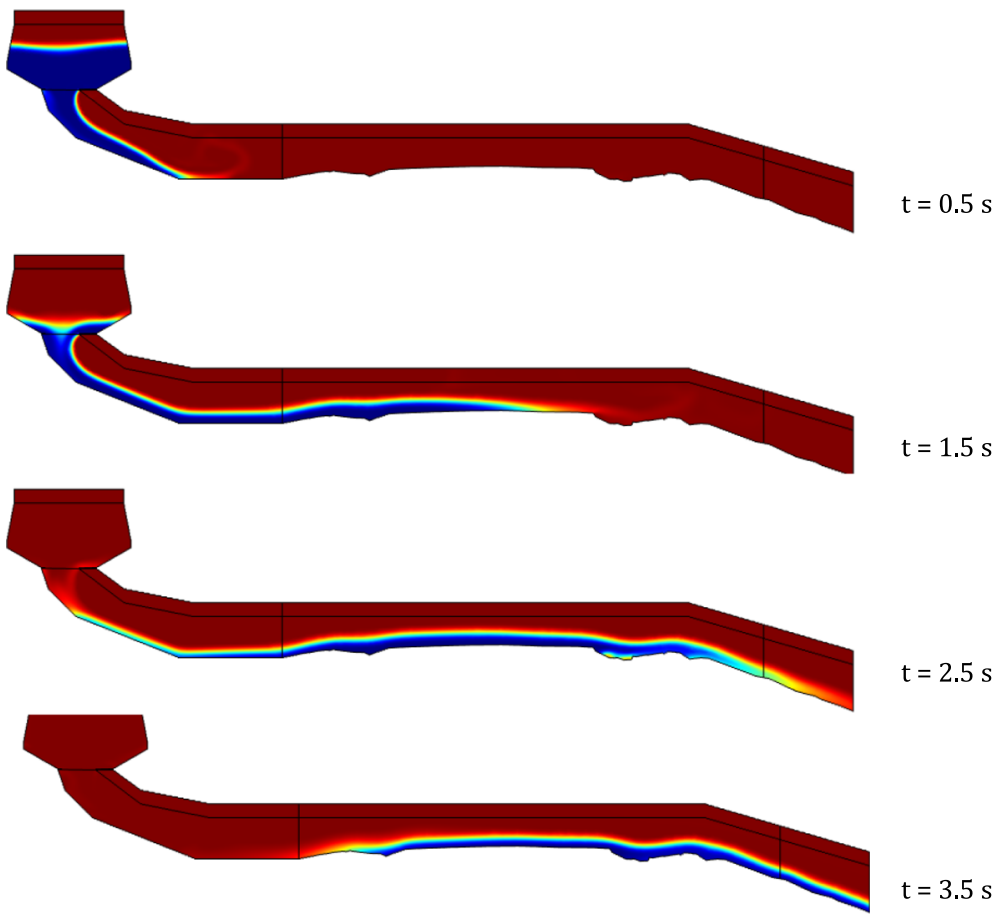

Fig. 11 Snapshots of the hydrodynamic CFD simulation at several times

Table 5 Validation of the hydrodynamic conditions at the simulator outlet for velocity ( $v_{\text {outlet }}$ ), depth $\left(h_{\text {outlet }}\right)$ and time from start to end of the overtopping wave $\left(T_{\text {ovt }}\right)$, in which diff. represents the differences in $(\%)$ between field measurements (meas.) and simulation (sim.)

\begin{tabular}{llllllllll}
\hline $\begin{array}{l}\text { Volume } \\
\left(\mathrm{m}^{3} / \mathrm{m}\right)\end{array}$ & $\begin{array}{l}v_{\text {outlet }} \\
\text { meas. }(\mathrm{m} /\end{array}$ & $\begin{array}{l}v_{\text {outlet }} \operatorname{sim} . \\
(\mathrm{m} / \mathrm{s})\end{array}$ & $\begin{array}{l}\text { Diff. } \\
(\%)\end{array}$ & $\begin{array}{l}h_{\text {outlet }} \\
\text { meas. }(\mathrm{m})\end{array}$ & $\begin{array}{l}h_{\text {outlet }} \\
\text { sim. }(\mathrm{m})\end{array}$ & $\begin{array}{l}\text { Diff. } \\
(\%)\end{array}$ & $\begin{array}{l}T_{\text {ovt }} \\
\text { meas. } \\
(\mathrm{s})\end{array}$ & $\begin{array}{l}T_{\text {ovt }} \\
\text { sim. }\end{array}$ & $\begin{array}{l}\text { Diff. } \\
(\%)\end{array}$ \\
\hline 0.15 & 2.95 & 3.05 & +3 & 0.10 & 0.05 & -50 & 1.48 & 2.4 & +62 \\
0.40 & 3.43 & 3.01 & -12 & 0.13 & 0.10 & -23 & 2.05 & 2.35 & +15 \\
0.70 & 4.10 & 3.57 & -13 & 0.15 & 0.14 & -7 & 2.38 & 2.6 & +9 \\
1.00 & 4.62 & 3.76 & -19 & 0.18 & 0.16 & -11 & 2.78 & 2.9 & +4 \\
1.50 & 4.84 & 4.11 & -15 & 0.20 & 0.19 & -5 & 3.40 & 3.10 & -9 \\
\hline
\end{tabular}

both in simulation and in observation. Therefore, depth measurements are generally less reliable than velocity measurements.

Additionally, the hydrodynamic conditions at location SM4 on the landside slope are validated. Table 2 shows that two tests of a single overtopping wave will not result in exactly the same hydrodynamic conditions, i.e. maximum velocity and water depth. For validation the values closest to the simulated conditions are used, assuming that the two measured values are the bandwidth of the hydrodynamic conditions of the wave volumes. This procedure results in a deviation range of $-0.1 \%$ till $-0.4 \%$ between measured and 
simulated maximum velocities at test location SM4 (Table 6). Simulating velocities accurately is of great importance since flow velocities are the main determinant of erosion development. The validation results show that maximum velocities at SM4 are in good agreement with measurements. However, again the simulated water depths deviate from the hydraulic measurements. The simulated water depths are between 0.01 and $0.04 \mathrm{~m}$ larger than was measured. These values show that the hydrodynamic model cannot fully represent the small water depths of the overtopping tongues. However, in this study we focus on flow velocities rather than water depths since this has a larger influence on the erosion onset. Therefore, we accept the overestimation of the simulated water depths. The water depth of the $1.50 \mathrm{~m}^{3} / \mathrm{m}$ wave is better predicted compared to the smaller overtopping volumes. This may be explained, because the transition gaps have a larger influence on the hydrodynamic conditions of small overtopping volumes. Besides, the differences can be caused by small errors in the field measurements since water depths in highly turbulent flows are hard to measure.

The maximum velocities at location SM4 show good agreement with measurements (Fig. 12), as shown in Table 6. The gradual decrease in flow velocity shows reasonable agreement with the measurements up till circa $t=2 \mathrm{~s}$. Afterwards, the simulated flow velocities are overestimated. This overestimation is probably caused by the fact that the CFD model computes velocities for both air and water. The high velocities at the tail of the overtopping wave can be a result of the velocities of the air rather than by the velocities of the water. However, it is not possible to distinguish between the velocity of water, the velocity of air, or a mixture of both in a single grid cell. In further research, this distinction should be considered. However, the front edge of the overtopping tongue with high velocities mainly influences erosion development since the critical flow velocity for poor grass quality equals $3.4 \mathrm{~m} / \mathrm{s}$ (Hoffmans et al. 2008), corresponding with the assumed grass quality in the model. Therefore, the inaccuracies in the simulated velocities at the end of the overtopping wave will not have much effect on the total erosion development.

The validation results show that velocities are in good agreement with measurements and water depths are simulated reasonably along the dike profile for most volumes. Figure 12 and Table 6 also show that the velocity profiles, especially at the front of the wave with high velocities, and the overtopping times are reasonably accurate. These results give enough confidence in an accurate representation of the hydrodynamic processes in the model. Therefore, we expect that the hydrodynamic model is also capable of predicting the friction velocities (used to compute bed shear stresses) along the dike profile with reasonable accuracy. Unfortunately, no measurements were available to validate the bed shear stresses explicitly.

Table 6 Validation of hydrodynamic conditions at measurement location SM4 (Fig. 2), in which diff. denotes the differences in (\%) between field measurements (meas.) and simulation (sim.)

\begin{tabular}{lllllll}
\hline $\begin{array}{l}\text { Volume }\left(\mathrm{m}^{3} /\right. \\
\mathrm{m})\end{array}$ & $\begin{array}{l}v_{\mathrm{SM} 4} \text { meas. } \\
\mathrm{s})\end{array}$ & $\begin{array}{l}v_{\mathrm{SM} 4} \operatorname{sim} .(\mathrm{m} / \\
\mathrm{s})\end{array}$ & $\begin{array}{l}\text { Diff. } \\
(\%)^{*}\end{array}$ & $\begin{array}{l}h_{\mathrm{SM} 4} \text { meas. } \\
(\mathrm{m})\end{array}$ & $\begin{array}{l}h_{\mathrm{SM} 4} \text { sim. } \\
(\mathrm{m})\end{array}$ & $\begin{array}{l}\text { Diff. } \\
(\%)^{*}\end{array}$ \\
\hline 0.40 & 4.45 & 4.43 & -0.4 & 0.02 & 0.03 & +51 \\
1.00 & 5.12 & 5.12 & -0.1 & 0.06 & 0.10 & +59 \\
1.50 & 5.55 & 5.57 & -0.4 & 0.10 & 0.13 & +35
\end{tabular}

*Percentage difference of the simulated velocity and water depth, compared to the closest value of the two measurements (see Table 2) 
- - Measured velocities 1

--- Measured velocities 2

Simulated velocities

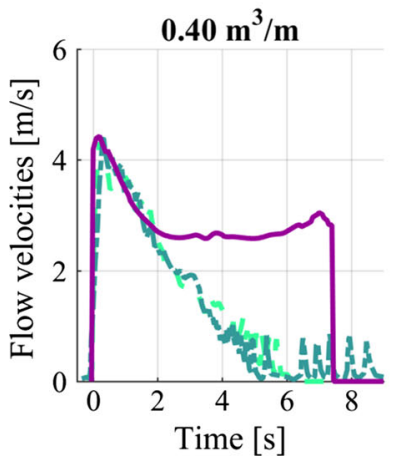

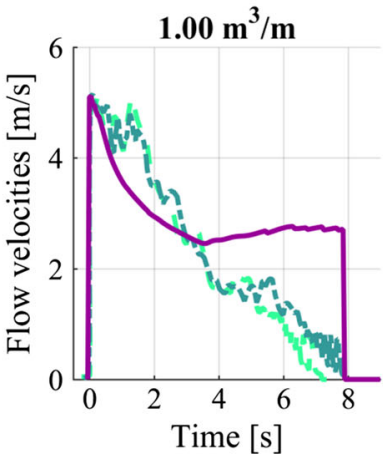

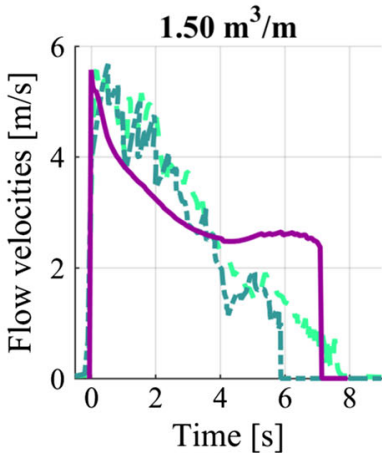

Fig. 12 Measured and simulated velocities at location SM4 for three volumes as a function of time

\subsection{Validation erosion model}

Validation of the erosion model focuses on the landside transition gap, since this location is most vulnerable to erosion onset. Validation is performed after $3 \mathrm{~h}$ of testing with a discharge of $0.05 \mathrm{~m}^{3} / \mathrm{s} / \mathrm{m}$, since the model was only developed to simulate erosion onset (Fig. 13). The $3 \mathrm{~h}$ of testing represents approximately 1500 waves. The root-mean-square error (RMSE) of the measured and simulated profiles at the landside transition (between $x=2.4$ and $x=2.8 \mathrm{~m}$ ) after $3 \mathrm{~h}$ of testing is equal to $3.8 \mathrm{~cm}$. The subsoil at the test section consisted of sand foundation below the road (between $x=2.0$ and $x=2.4 \mathrm{~m}$ ) and of clay onwards.

The location and order of magnitude of the erosion onset are modelled with reasonable accuracy. However, the measurements showed a temporary increase in the dike profile, while the simulated results only showed degradation of the dike profile. This can be explained by the folding process of grass. During the field observations the grass cover was folded upwards before it was pulled out. Folding of the grass cover leads to a temporary

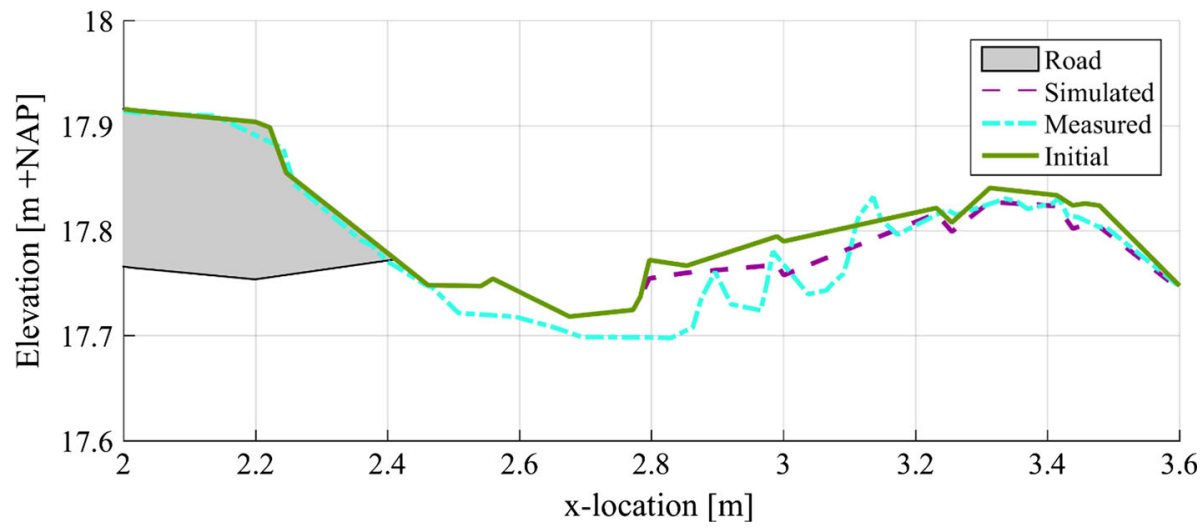

Fig. 13 Measured and simulated dike profile after $3 \mathrm{~h}$ of $0.05 \mathrm{~m}^{3} / \mathrm{s} / \mathrm{m}$ test and initial profile 
increase in the dike profile at these locations. This process was not modelled during the simulation and leads to temporal random variations between the observations and simulation. However, this had little effect on the longer-term evolution of the erosion depth. Furthermore, the model does not predict erosion between $x=2.4$ and $x=2.8 \mathrm{~m}$, while a significant scour was measured during the erosion test. This difference is caused by the assumption of an undamaged grass sod along the dike profile in the model. In reality, the gaps next to the road were damaged by traffic. Therefore, the overtopping wave directly hits the bare clay sod and extensive erosion followed immediately. In a future research, detailed measurements of the grass cover thickness and substrate, which were not available, need to be included in the model to improve the model prediction in this region near the road. Besides, the values of the parameters described in Sect. 3.2 were taken from the literature and field experiments, or determined during the calibration procedure of the erosion model. With the use of these values, the erosion model does not predict the erosion onset correctly and need to be adjusted to enable accurate prediction of the erosion development in time. However, data were limited and therefore further calibration of the soil composition and soil parameters was not possible. More detailed observations are required to improve the erosion prediction.

The simulated erosion profile after $x=3.2 \mathrm{~m}$ is close to what was measured in the field. Both profiles show a maximum erosion depth of approximately $1 \mathrm{~cm}$. During the field experiment, extensive erosion occurred in the section $x=2.4$ till $x=3.2 \mathrm{~m}$. The erosion became so large that head cut erosion started to occur. This period was excluded from the analysis since the model is only valid to predict erosion onset till a depth of $20 \mathrm{~cm}$. The erosion after $x=3.2 \mathrm{~m}$ stayed limited during the entire field experiment, which corresponds with the predictions of the model.

Discrepancies between the measured and simulated erosion profile can be explained by the assumptions made during the modelling process. However, the location and average depth of the large-scale processes were predicted with sufficient accuracy to get insight into the dominant location of erosion onset. The model is not appropriate to simulate erosion deeper than $20 \mathrm{~cm}$, because head cut type of erosion cannot be simulated, due to the underlying model assumptions. Although the model is not capable of simulating the small-scale variations on erosion development, it provides sufficient insight to be able to investigate the effects of a road structure on top of a dike on the location of erosion onset.

\section{Effect of a road}

We used the coupled hydrodynamic-erosion model to study the effects of a road located at the crest of a dike on the erosion onset during wave overtopping. The focus lies on the landside transition since the field experiment showed that most erosion will evolve at that location. The objective of this case study is to find the most vulnerable location in terms of erosion onset for different dike geometries. To reach this objective it is not needed to simulate the Weibull distribution of an actual storm. Instead, we only use a single wave volume which reduces the amount of simulations needed. It does not influence the general conclusions since the effect of roughness on erosion onset is independent of a storm condition. The $1.5 \mathrm{~m}^{3} / \mathrm{m}$ wave volume was simulated since this was the maximum wave volume that was routed during the validation procedure of the model and will result in the most scour. For the simulations in this section the resulting scour is computed after routing 100 waves with a volume of $1.5 \mathrm{~m}^{3} / \mathrm{m}$ and updated dike profiles were constructed. This 
process is repeated three times to simulate 300 overtopping waves in total such that an erosion depth of at least $10 \mathrm{~cm}$ was predicted corresponding with failure, i.e. the depth of the grass layer. For future work we advise to include the randomness of overtopping waves as for an actual storm in the analysis.

The following cases are simulated: (1) irregular dike profile with a road on top (corresponding with the situation in Millingen aan de Rijn, used for validation), (2) irregular grass-covered dike profile and (3) smooth dike profile without geometrical irregularities with a road on top. From now on, we refer to a smooth dike profile when no geometrical irregularities are present in the dike profile.

The effect of the road section can be divided into two aspects, namely effects as a result of a lower roughness due to the road surface and effects caused by small-scale geometrical irregularities (damaged transitions) in the dike profile. Comparing cases (1) and (2) indicates the effects of bed roughness, while comparing cases (1) and (3) yields the effects caused by geometrical roughness.

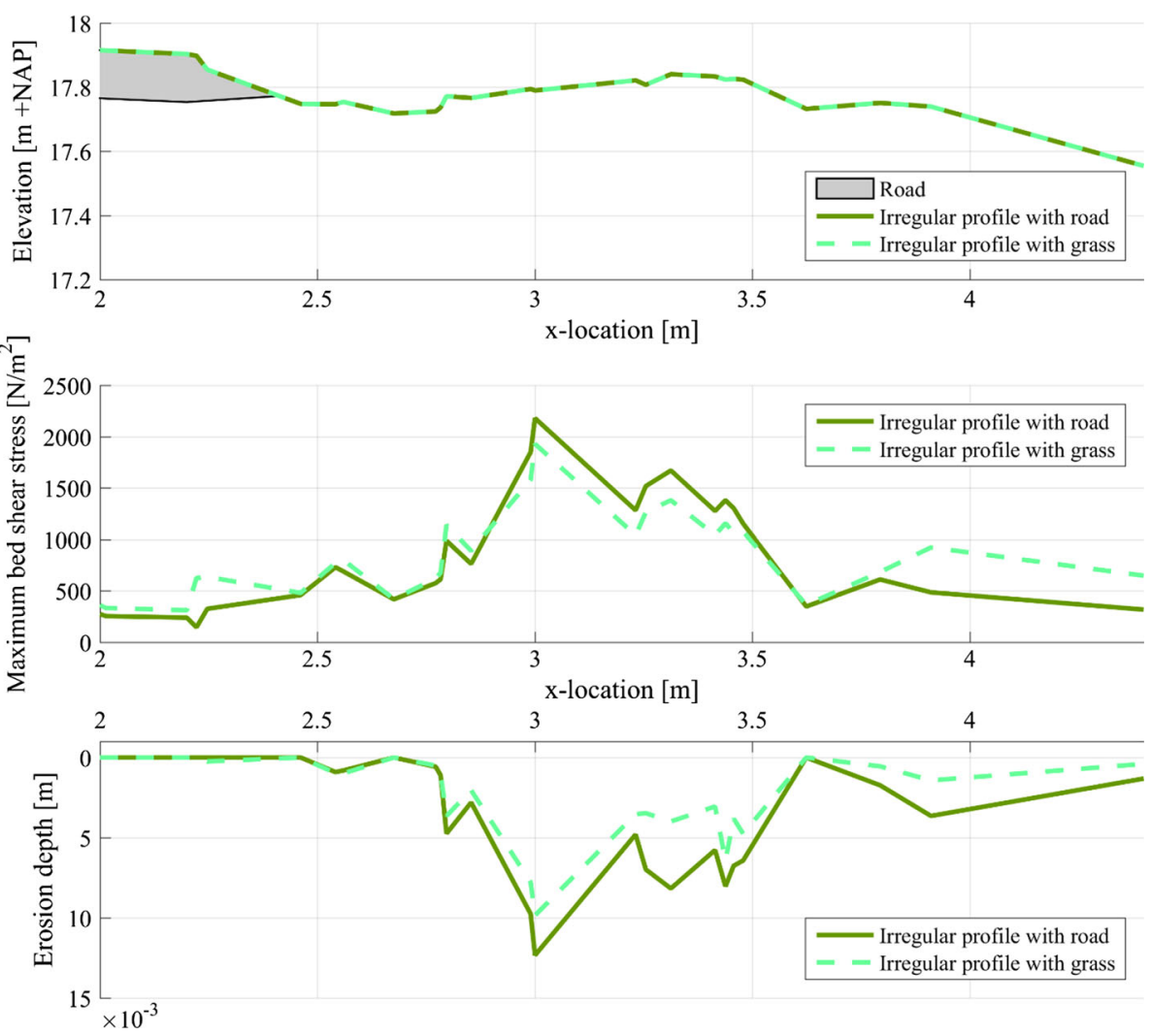

Fig. 14 Dike profiles, maximum bed shear stresses and erosion depths of the landside transition for an irregular dike profile with (case 1) and without (case 2) a road on top after 300 waves with a volume of $1.50 \mathrm{~m}^{3} / \mathrm{m}$ 


\subsection{Bed roughness effect}

The results of cases (1) and (2) (Fig. 14) show that the erosion pattern of the two profiles are almost identical before location $x=2 \mathrm{~m}$, since the bed shear stress does not or slightly exceed the critical bed shear stress threshold here. Case (2) predicts less erosion after $x=2 \mathrm{~m}$. The higher bed roughness of the grass cover leads to more energy dissipation, and therefore, the overtopping wave is slowed down more. This results in a decrease in the bed shear stresses and thus in a decrease in the amount of scour in the landside transition. In simulation (1), there is a sudden increase in the bed roughness caused by the transition of the asphalt layer with the grass cover. This transition yields locally higher bed shear stresses caused by local flow turbulence (Morris 2012). Along the slope of the dike profile, higher bed shear stresses are computed for case (2) compared to case (1). However, the time at which the bed shear stress exceeds the critical bed shear stress was larger for case (1) compared to case (2). For this reason more erosion is predicted along the slope for the irregular profile with a road on top, even though the maximum bed shear stress is lower compared to the irregular grass covered profile. This shows that besides the simulated maximum bed shear stresses, also the duration that the bed shear stresses exceed the critical bed shear stress is of importance.

Figure 15 shows the average kinematic energy in time $(\overline{k(t)})$ for both cases. The red values correspond with the locations where high turbulence occurs, showing that more turbulence is expected in the transition zone when two covers with different roughnesses are present such as in case (1). However, erosion is not solely initiated by turbulence. Also high bed shear stresses due to high flow velocities may initiate erosion onset. Therefore, the kinematic energy in time is multiplied $(\overline{k(t)})$ with the mean flow velocity $(\overline{U(t)})$. The resulting factor is called the average turbulent erosive potential from now on and is shown in Fig. 15. Since the grass strength is assumed to be homogeneous along the dike profiles, the average turbulent erosive potential shows the locations with the highest potential for erosion onset. The irregular grass-covered dike profile is less vulnerable to erosion onset, since it shows a lower potential, especially along the upper part of the slope. This
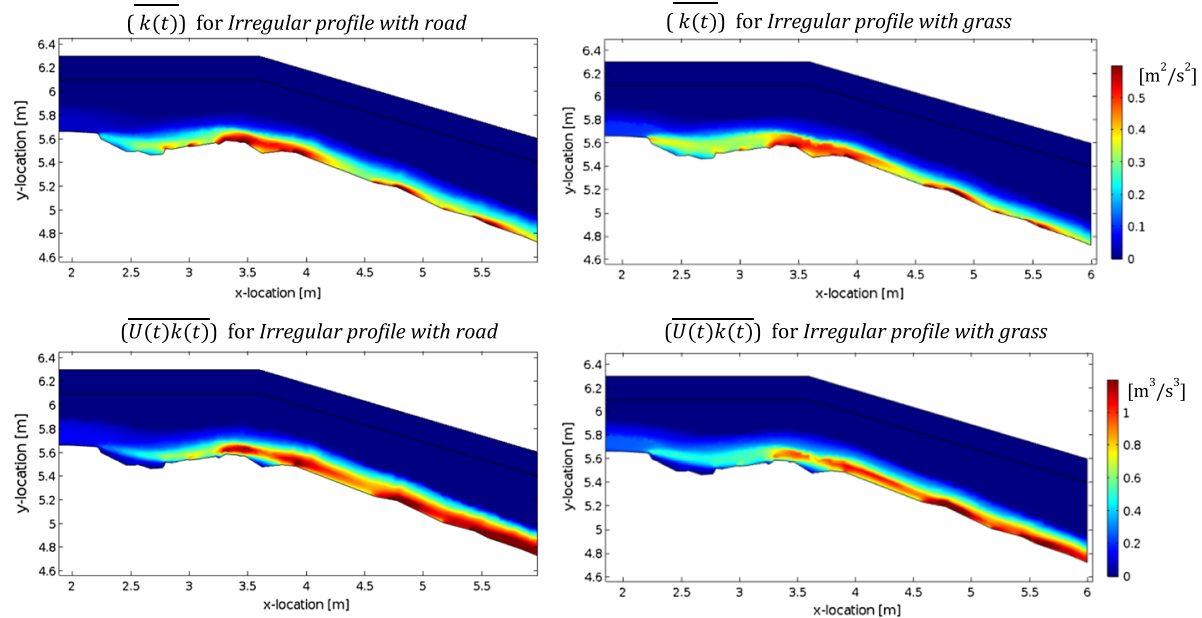

Fig. 15 Average kinetic energy $(\overline{k(t)})$ and average turbulent erosive potential $(\overline{U(t) k(t)})$ for an irregular dike profile with (case 1) and without (case 2) a road on top caused by a wave with a volume of $1.50 \mathrm{~m}^{3} / \mathrm{m}$ 
corresponds with the earlier explanation of more energy dissipation in case when the dike profile is fully covered with grass.

The results show that the roughness of the road section leads to higher erosion at the landside transition, because energy loss is focused in one location. This process results in deeper scour holes. However, the increase in erosion due to the asphalt cover is relatively small, since it only increases the maximum scour depth by $14 \%$.

\subsection{Geometrical roughness effect}

Figure 16 shows that during wave overtopping lower bed shear stresses and hence less erosion are predicted for case (3) than for case (1). In the transition zone, there is a significant lowering of the bed shear stress with a factor 5 until $x=3 \mathrm{~m}$, just upstream of the start of the landward slope. This causes the decrease in scour depth at the landside transition from a maximum of $13 \mathrm{~cm}$ to a maximum of $4 \mathrm{~cm}$. Also the location of the maximum scour depth shifted from near the transition towards just upstream of the brink point.

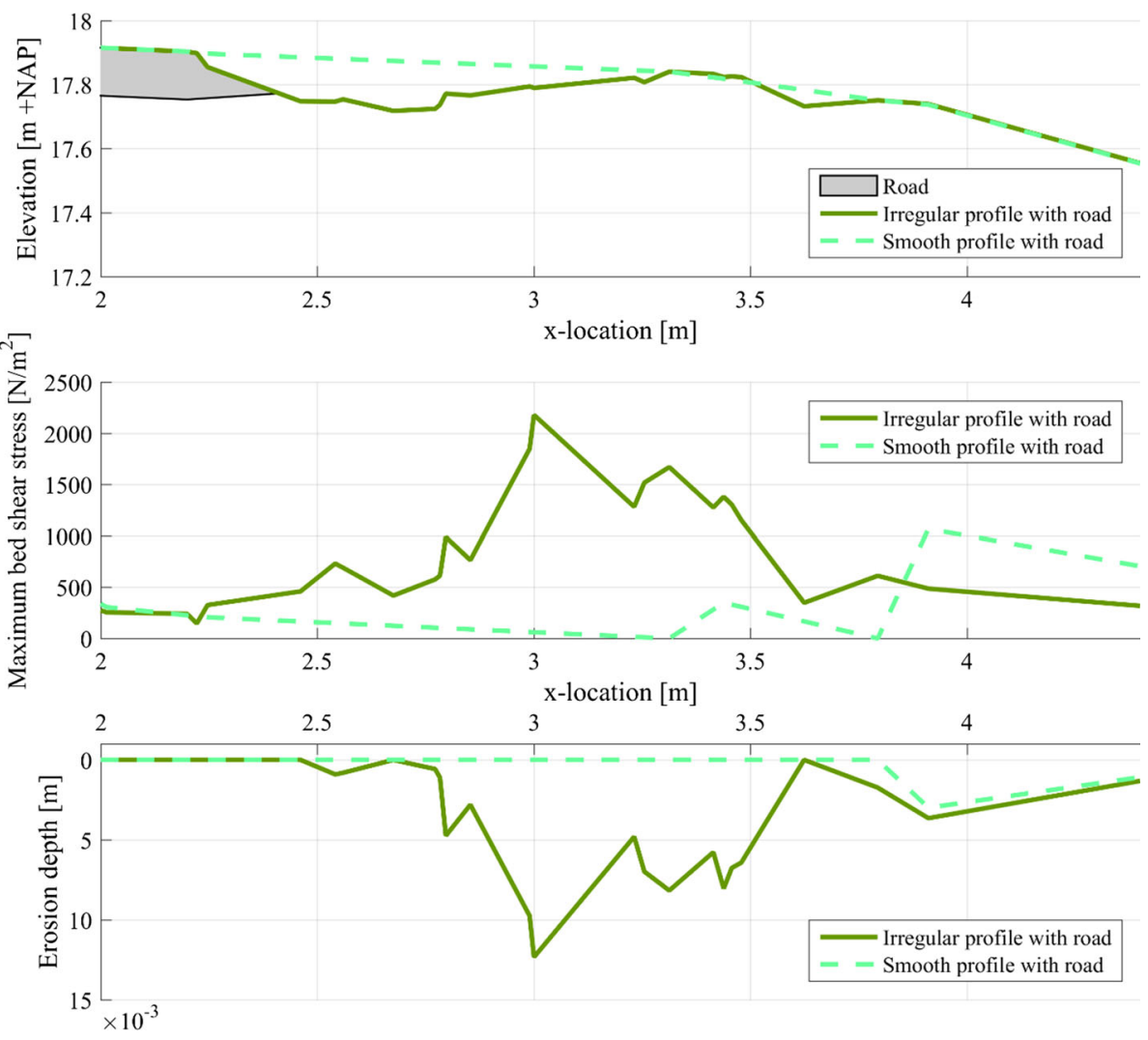

Fig. 16 Dike profiles, maximum bed shear stresses and erosion depths of the landside transition for an irregular dike profile with a road on top (case 1) and a smooth dike profile with a road on top (case 3) after 300 waves with a volume of $1.50 \mathrm{~m}^{3} / \mathrm{m}$ 

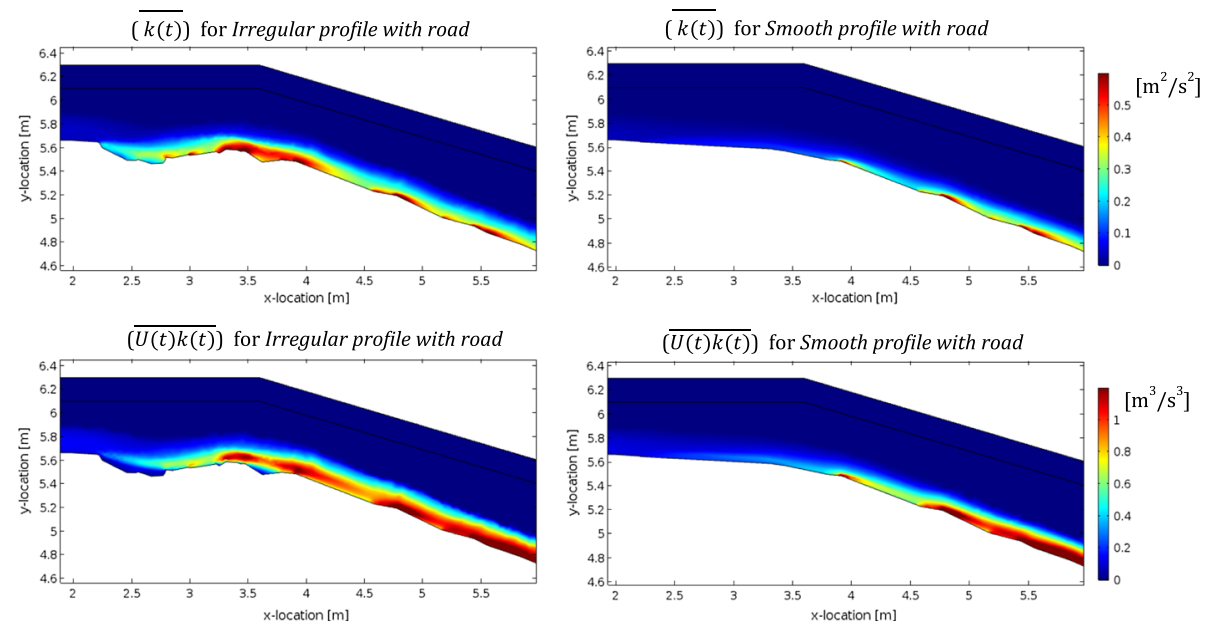

Fig. 17 Average kinetic energy $(\overline{k(t)})$ and average turbulent erosive potential $(\overline{U(t) k(t)})$ for an irregular dike profile with a road on top (case 1) and a smooth dike profile with a road on top (case 3 ) caused by a wave with a volume of $1.50 \mathrm{~m}^{3} / \mathrm{m}$

Although more erosion is predicted for an irregular dike profile, Fig. 16 shows that the maximum bed shear stresses along the upper part of the slope are lower for case (1) compared to case (3). The damaged transition gaps lead to loss of energy and therefore to lower flow velocities along the dike slope. For the smooth profile less energy is dissipated, leading to higher velocities along the dike slope and therefore to higher bed shear stresses. Therefore, erosion development along the slope might be expected. However, it must be noted that this region is beyond the model boundary and therefore we cannot study the erosion effects at these locations.

Also Fig. 17 shows that erosion onset is mainly affected by irregularities in the dike profile, where the average kinetic energy and average turbulent erosive potential are shown. High turbulence occurs at locations where irregularities in the profile are present. Although turbulence along the smooth dike profile is relatively low, the erosion potential increases significantly along the dike slope due to acceleration of the flow.

In reality, for a smooth grass-covered dike without geometrical irregularities in the profile, erosion is expected to evolve at the toe of the dike and the lower part of the dike slope (Oumeraci et al. 2005). We showed that the location of erosion onset is sensitive to the geometry and roughness of the dike crest upstream. Extending the model to include the dike slope beyond the dike toe can provide further insight into the location and magnitude of erosion onset and the effect of transitions on the crest and slope.

\section{Discussion}

A coupled hydrodynamic-erosion model was developed based on the turf-element model of Hoffmans (2012) combined with a depth and time dependency based on the work of Dean et al. (2010), Hughes (2011) and Valk (2009). Erosion was computed based on bed shear stresses time series. The time-dependent function leads to a more detailed erosion model than used in the literature so far. We are aware of the fact that the erosion model 
developed in this study is just a simplification of the reality. However, it is the best method available at the moment. Besides, to reach the objective of this study it was not necessary to model the complexity of the grass cover exactly. It was important to investigate the large-scale pattern of changes in erosion onset as a result of a structure such as a road, which is still possible to study in case of simplified conditions. In this section the assumptions of the erosion model are discussed in more detail.

The erodibility processes of a grass sod with underneath a clay layer is very complex. A grass cover can be split in two layers: the topsoil where the root structure provides normal and lateral strength and connects the small clayey aggregates that prevents them from being washed out during an overtopping event, and the subsoil where the clay layer is stiffer and less permeable, without roots (Hoffmans 2012). During an overtopping event the following forces act on the grass sod: (1) a lift force caused by pressure fluctuations on the grass cover (underpressure), (2) the strength of the grass cover and clay layer as a result of its weight, (3) the frictional forces between clay particles and (4) root tensile forces (Hoffmans 2012). During wave overtopping firstly the grass sod is damaged and thereafter the aggregated clay particles are washed out when the bed shear stress exceeds the critical bed shear stress, which depends on the forces mentioned above. After extensive scour of the aggregated clay layer, the roots of the grass sod are exposed to the flow and will be pulled out (Oumeraci et al. 2005; Quang and Oumeraci 2012). Eventually, the grass sod will fail which will result in a significant erosion of the underlying clay layer. This process was also observed by experiments performed with the WOS (Dutch Ministry of Infrastructure and the Environment 2012). The complex physics observed are highly simplified by the erosion model leading to differences between the model and field experiments:

- The model uses the physics of slit erosion (e.g. layers of soil are eroded consecutively) to enable the prediction of the erosion of the grass cover and clay layer. This means that the model immediately predicts scour of the grass sod, while in reality, firstly the clay aggregates between the roots are washed out and grass sods are pulled out or weakened by underpressure. Additionally, the model is not capable of simulating the folding processes of a grass cover which was observed during the field experiment. However, the results show that the predicted erosion pattern along the slope is reasonably well predicted: locations of large scour are close to the observations and the order of magnitude of erosion depth is simulated well. This indicates that although the assumption of slit erosion is not capable of predicting the small-scale processes, the slit erosion is capable of predicting the general trend and order of magnitude of the erosion pattern. The prediction of the small-scale erosion pattern would require a fundamentally different erosion model, in which lifting of the grass sod due to underpressure and pulling out and folding of the grass sods are included. Setting up such a detailed erosion model is a huge challenge, but the hydrodynamic model is in principle capable of computing the required input.

- The field experiment showed that the grass quality differed significantly along the dike profile, whereas the model assumes a homogenous grass strength. During the field experiment, the grass sod located next to the road section was damaged, leading to extensive erosion in this zone. Since the model did not include these damages almost no erosion was predicted between $x=2.4 \mathrm{~m}$ and $x=2.8 \mathrm{~m}$ (Fig. 13). A more detailed description of the soil structure and strength parameters in this zone needs to be tested to improve the predicted erosion near the road-grass transition.

- The model assumes that the complete grass cover is eroded at a scour depth of $10 \mathrm{~cm}$. We used a depth-dependent erosion resistance to account for the reduced strength of 
grass after erosion of the top layer. In reality, the root system is much more complex with different root lengths and strengths. This can explain the small-scale differences between the observations and predicted erosion. However, the results show that the depth-dependent erosion model is quite capable of describing the general erosion trend at locations downstream of $x=2.8 \mathrm{~m}$ up to a depth of $20 \mathrm{~cm}$.

- An assumption was made about the linear increase in the clay cohesion over depth. It may be expected that the clay cohesion indeed increases till a certain depth. However, most probably it will reach an equilibrium state. Therefore, the linear increase seems not very realistic, while it has a large influence on the erosion resistance. This limits the applicability of the model till a depth of approximately $20 \mathrm{~cm}$. In further studies, we recommend to extend the erosion equation towards such an equilibrium value, so the model is valid up to depths of $0.5-1 \mathrm{~m}$. This would enable further validation of the model for larger erosion depths.

- The composition of the materials was simplified in the model schematization. The field experiment showed that debris and sand at the road shoulders were present. Sand erodes easier than cohesive clay, which leads to discrepancies between measured and simulated erosion depths. The model is capable of including this complex composition by including a layered structure in the depth-dependent erosion equation and adding spatial variability along the slope. How this might affect the erosion rate is recommended for further study.

- During a real storm (and during the field experiment), the overtopping tongue flows over the crest and some water will remain in the gaps of the dike profile. When a new wave overtops, the bed shear stresses at these gaps are lower caused by the damping effect of the water layer that is present in the gaps. This process is not considered in the CFD simulation since every overtopping wave is modelled on a dry slope. In particular, for small discharges this may lead to an overestimation of the bed shear stresses during the overtopping process. It is expected that the effect will be lower for large discharges since the wave forces will be higher. The validation, however, did not show that the thin water layers in the gaps had a significant effect. Therefore, the damping effect is most probably negligible, justifying the assumption of a continuously dry slope.

The erosion model uses the soil parameter $E_{\text {soil }}$ which can be used when the amount of erosion is computed based on the maximum bed shear stress. However, the parameter was not adjusted for a time-dependent formula. This may lead to slight underestimation of the scour development, since a lower soil parameter is most probably more suitable in cases when bed shear stresses in time are considered. In this study a value of $3.70 \times 10^{7} \mathrm{~m} / \mathrm{s}$ along the crest and a value of $1.07 \times 10^{8} \mathrm{~m} / \mathrm{s}$ along the slope were assumed based on the measured depth-averaged turbulence intensities along the crest (0.17) and slope (0.10) (Van Hoven et al. 2013). The resulting values for $E_{\text {soil }}$ are considerably higher than the values mentioned by Hoffmans et al. (2008) and are most probably overestimated.

A brief sensitivity analysis was performed to determine the influence of the most uncertain parameters on the computed output. We found that decreasing the Nikuradse roughness height of the grass sod with a factor $10(6.8 \mathrm{~mm})$ results in an increase in the maximum erosion onset of $18 \%$. Replacing the maximum roughness value of steel given by Chow (1959) with the minimum value, the maximum erosion only changes with $3.6 \%$. We can therefore conclude that the roughness parameters only have a little effect on the simulated erosion onset. More important are the assumptions made on the strength parameters of the grass sod and clay layer. We found that decreasing the clay cohesion and the grass strength with $50 \%$, the maximum erosion increases approximately 87 and $66 \%$, 
respectively. We can therefore conclude that the assumptions on the strength parameters of the erosion model highly influence the predicted erosion. However, it has no influence on the location of erosion onset which was the main focus of this study.

In addition, we found that the erosion model is highly sensitive to the depth-averaged turbulence intensities. Only increasing this parameter with $10 \%$ along the crest already results in an increase in the maximum erosion of $31 \%$. In this study, the measured depthaveraged turbulence intensities along the crest (0.17) and slope (0.10) are used as input parameters of the erosion model. The depth-averaged turbulence intensities predicted by the hydrodynamic model can be computed with the following formula:

$$
r_{0}=\frac{\sqrt{k}}{U_{0}},
$$

in which $k$ represents the average kinetic energy $\left(\mathrm{m}^{2} / \mathrm{s}^{2}\right)$ and $U_{0}$ the depth-averaged flow velocity $(\mathrm{m} / \mathrm{s})$. The computed depth-averaged kinetic energy along the slope $(1.2 \mathrm{~m}$ after the transition crest-slope) equals $63.3 \times 10^{-2} \mathrm{~m}^{2} / \mathrm{s}^{2}$ for the $1.5 \mathrm{~m}^{3} / \mathrm{m}$ wave volume, and the maximum depth-averaged flow velocity for this volume equals $5.6 \mathrm{~m} / \mathrm{s}$ (Fig. 12). Using formula 15 results in a depth-averaged turbulence intensity of 0.14 . This value is in line with the field measurements. Therefore, it is valid to use the measured depth-averaged turbulence intensities as input of the erosion model and it has no large effects on the model outcomes. However, in future work also the computed depth-averaged turbulence intensities can be used as input.

The model results show that a road section leads to greater erosion onset at the crest of the dike profile at the landside of the road. This was also observed in the experiment. During other experiments performed with the WOS it was found that for a grass-covered dike without a road most erosion evolves at the toe of the dike (Van der Meer et al. 2010). A preliminary simulation (not reported in this paper) with our model including the dike toe showed that due to the increasing amount of scour at the crest, the erosion at the toe decreased. This implies that the location of the initiation of scour due to wave overtopping may shift from the toe to the crest, which affects breach development. Further study is needed to determine which scour location is most vulnerable to dike failure. This may be studied with the use of dike breach models. Additionally, we recommend also investigating the effect of the location of scour on the interaction with other failure mechanisms (e.g. macro-stability) in a future study.

This study used measured dike geometries of the experiment in Millingen aan de Rijn and hence corresponding soil properties. However, the results can also be transferred to other cases. Dike geometry can easily be adapted as well as grass and soil properties, making this model appropriate to investigate erosion patterns of any dike. Erosion of dikes with other cover vegetation and soil core can be computed by adapting the bed roughness in the hydrodynamic model and the strength terms in the erosion model. Since the input parameters of the coupled hydrodynamic-erosion model can easily be adapted, the model is applicable for understanding the erosion processes. However, we recommend further testing and verifying the results on other dike types and locations. Additionally, we recommend verifying the applicability of the model for coastal wave conditions (e.g. long waves), since the model was validated for small waves (river conditions) only in this study. 


\section{Conclusions}

The coupled hydrodynamic-erosion model was developed and applied to quantify the influence of a road structure on the erosion pattern of a grass-covered dike due to wave overtopping. The simulated maximum velocities at the crest were simulated within $20 \%$ of the measurements, while maximum velocities at the slope were well predicted with a deviation of less than $0.5 \%$ compared to field measurements. Additionally, the simulated location of maximum erosion is similar to the observed location of maximum erosion. So, although the accuracy of some details was limited, both hydrodynamics and location of erosion onset showed good trends. More quantitative data under other conditions (dike geometry, grass quality, etc.) are needed to further validate and improve the model. The validation gave sufficient confidence to apply the model for two cases: a dike without the road, but with the geometrical irregularities, and a dike with a road, but without the geometrical irregularities.

Comparing a dike with and without a road showed that the location of erosion onset is highly sensitive to geometrical irregularities in the dike profile, since irregularities yield an increase in the near-bed turbulence. Additionally, the lower roughness of an asphalt road leads to more erosion at the landside transition zone caused by higher flow velocities and increased local flow turbulence compared to an irregular dike profile completely covered with grass. Both the geometrical roughness and bed roughness affect erosion onset, but the geometrical roughness effect is much more significant. Although this is a first attempt to model grass cover erosion in such detail, the results are promising. Further testing on a range of transitions and geometries is therefore recommended.

Acknowledgements This research is supported by the Netherlands Organisation for Scientific Research (NWO), which is partly funded by the Ministry of Economic Affairs. The authors would like to thank GosseJan Steendam from INFRAM, Andre van Hoven from Deltares, and Jentsje van der Meer from Van der Meer Consulting B.V. for providing the data. In addition, the authors would like to thank the two anonymous reviewers for comments and suggestions, which greatly improved the quality of the paper.

Open Access This article is distributed under the terms of the Creative Commons Attribution 4.0 International License (http://creativecommons.org/licenses/by/4.0/), which permits unrestricted use, distribution, and reproduction in any medium, provided you give appropriate credit to the original author(s) and the source, provide a link to the Creative Commons license, and indicate if changes were made.

\section{References}

Bakker J, Melis R, Mom R (2013) Factual report: Overslagproeven Rivierenland. INFRAM, Project number: 12i071, Version 1.0, Marknesse

Chow VT (1959) Open-channel hydraulics. McGraw-Hill Book Company Inc., New York

ComCoast (2007) Workpackage 3: Development of alternative overtopping-resistant sea defences. Phase 3: design, construction, calibration and the use of the wave overtopping simulator. Project Number: 04i103, Delft

COMSOL bv (2012) Comsol multiphysics user's guide version 4.3. ISBN: 1781273332

Dean RG, Rosati JD, Walton TL, Edge BL (2010) Erosional equivalences of levees: steady and intermittent wave overtopping. Ocean Eng 37:104-113. https://doi.org/10.1016/j.oceaneng.2009.07.016

Dutch Ministry of Infrastructure and the Environment (2012) Handreiking Toetsen Grasbekledingen op Dijken t.b.v. het opstellen van het beheersoordel (BO) in de verlengde derde toetsronde. The Hague, the Netherlands. http://publications.deltares.n1/WeL1947.pdf

EurOtop (2007) Wave overtopping of sea defences and related structures: assessment manual, Kuste. Boyens Offset. ISBN: 978-3-8042-1064-6 
Hoffmans G (2012) The influence of turbulence on soil erosion. Eburon Academic Publishers, Delft. ISBN 9789059726826

Hoffmans G, Akkerman GJ, Verheij H, Van Hoven A, Van der Meer J (2008) The erodibility of grassed inner dike slopes against wave overtopping. In: ASCE, Proceedings of ICCE 2008, Hamburg, pp 3224-3236. https://doi.org/10.1142/9789814277426_0267

Hughes SA (2011) Adaptation of the levee erosional equivalence method for the hurricane storm damage risk reduction system (HSDRRS). ERDC/CHL TR-11-3, U.S. Army Engineer Research and Development Center, Vicksburg, p 143

Hughes SA, Nadal NC (2009) Laboratory study of combined wave overtopping and storm surge over flow of a levee. Coast Eng 56:244-259. https://doi.org/10.1016/j.coastaleng.2008.09.005

Hughes SA, Thornton C, Van der Meer JW, Scholl B (2012) Improvements in describing wave overtopping processes. In: ASCE, Proceedings of ICCE 2012. Santander, Spain, pp 1-15. https://doi.org/10.9753/ icce.v33.waves.35

Launder B, Morse A, Rodi W, Spalding D (1972) The prediction of free shear flows-a comparison of the performance of six turbulent models. In: Proceedings of NASA conference on free shear flows

Le HT, Verhagen HJ, Vrijling JK (2017) Damage to grass dikes due to wave overtopping. Nat Hazards 86:849. https://doi.org/10.1007/s11069-016-2721-2

Morris M (2012) WP 3: reliability of urban flood defences-D.3.1 Guidance on improved performance of urban flood defences. Report Number: WP3-01-12-11

Nezu I, Nakagawa H (1991) Response of velocity and shear stress to abrupt irregularity of bed roughness in streams. In: 24th Congress of IAHR. Delft, The Netherlands, pp 235-242

Nezu I, Nakagawa H (1995) Turbulence measurements in unsteady free-surface flows. Flow Meas Instrum 6:49-59. https://doi.org/10.1016/0955-5986(95)93458-7

Nezu I, Tominaga A (1994) Response of velocity and turbulence to abrupt changes from smooth to rough beds in open-channel flow. In: Symposium on fundamentals and advancements in hydraulic measurements and experiments, pp 195-204

Oumeraci H, D'Eliso C, Kortenhaus A (2005) Breaching of coastal dikes: state of the art. Braunschweig, LWI Report Number: 910

Quang TT, Oumeraci H (2012) Numerical modelling of wave overtopping-induced erosion of grasses inner sea-dike slopes. Nat Hazards 63:417. https://doi.org/10.1007/s11069-012-155-Z

Roelvink JA (2006) Coastal morphodynamic evolution techniques. Coast Eng 53(2):277-287. https://doi. org/10.1016/j.coastaleng.2005.10.015

Schuttrumpf H, Oumeraci H (2005) Layer thicknesses and velocities of wave overtopping flow at seadikes. Coast Eng 52:473-495. https://doi.org/10.1016/j.coastaleng.2005.02.002

Spalding DB, Launder BE (1974) The numerical computation of turbulent flows. Comput Methods Appl Mech Eng 3:269-289. https://doi.org/10.1016/0045-7825(74)90029-2

Sprangers JTCM (1999) Vegetation dynamics and erosion resistance of sea dyke grassland. Wageningen Algricultural University, Wageningen. ISBN 90-5485-999-7

Steendam GJ, Hoffmans G, Bakker J, van der Meer JW, Frissel J, Paulissen M, Verhei H (2012) SBW wave overtopping and grass cover strength. Predictions of prototype tests. Deltares reporst 1206016-007. Delft, The Netherlands

Steendam GJ, Van Hoven A, Van der Meer JW, Hoffmans G (2014) Wave overtopping simulator tests on transitions and obstacles at grass covred slopes of dikes. In: ASCE, proceedings of ICCE 2014, Seoul, South-Korea, pp 1-14

Tingsanchali T, Chinnarasri C (2001) Numerical modelling of dam failure due to flow overtopping. Hydrol Sci J 46(1):113-130. https://doi.org/10.1080/02626660109492804

Trung LH (2014a) Overtopping on grass covered dikes-resistance and failure of the inner slopes. Ph.D Thesis, Delft University of Technology, Delft. ISBN: 9789462591707

Trung LH (2014b) Velocity and water-layer thickness of overtopping flows on sea dikes. Report of measurements and formulas developed. Delft University of Technology, Delft. ISSN: 0169-6548

Valk A (2009) Wave overtopping impact of water jets on grassed inner slope transitions. TU Delft. Retrieved from: http://repository.tudelft.nl/view/ir/uuid:5ca03ac7-0296-4ccd-b7b0-e9485cfc934f/

Van der Meer JW, Bernardini P, Snijders W, Regeling W (2006) The wave overtopping simulator. In: ASCE, ICCE 2006. San Diego, pp 1-13. https://doi.org/10.1142/9789812709554_0390

Van der Meer JW, Schrijver R, Hardeman B, Hoven A. Van, Verheij H, Steendam GJ (2009) Guidance on erosion resistance of inner slopes of dikes from three years of testing with the Wave Overtopping Simulator. In: Proceedings of ICE 2009, pp 1-14. ISBN: 9780727741318

Van der Meer JW, Hardeman B, Steendam GJ, Schüttrumpf H, Verheij H (2010) Flow depths and velocities at crest and landword slope of a dike, in theory and with the wave overtopping simulator. In: Proceedings of ICCE 2010. ASCE, Shanghai 
Van Hoven A, Hardeman B, Van der Meer JW, Steendam GJ (2010) Sliding stability of landward slope clay cover layers of sea dikes subject to wave overtopping. In: Proceedings of ICCE. ASCE, Shanghai, p 12

Van Hoven A, Verheij H, HoffmanS G, Van der Meer JW (2013) Evaluation and model development: grass erosion test at the Rhine dike. Delft, Project Number: 1207811-002

Zhu Y (2006) Breach growth in clay-dikes. Technical University Delft, Delft. ISBN 9789090209647 